\title{
Nucleosome topology and DNA sequence modulate the engagement of pioneer factors SOX2 and OCT4
}

\author{
Fabiana C. Malaga Gadea ${ }^{1}$ and Evgenia N. Nikolova*,1 \\ ${ }^{1}$ Department of Biophysics, Johns Hopkins University, 3400 N. Charles Street, Baltimore, MD 21218 \\ *To whom correspondence should be addressed: \\ enikolova@jhu.edu
}

\begin{abstract}
Nucleosomes in eukaryotic genomes present a barrier to the competent binding of many regulatory proteins. Pioneer transcription factors (pTFs) can bind their target sites on nucleosomal DNA and collaborate with other factors to locally open chromatin and promote transcription. While the interaction of pluripotency pioneer factors and functional partners Sox2 and Oct4 with nucleosomes has been widely studied, molecular details about their engagement in different nucleosome contexts remain elusive. Here, using high-resolution nuclear magnetic resonance (NMR) spectroscopy and biochemical studies, we reveal site-specific structural and dynamic information about pTF interaction with nucleosomes. We find that the affinity of Sox2 and Oct4 to the nucleosome and their synergistic binding correlates with solvent-exposed sites but is highly position and DNA sequence dependent and linked to distinct pTF conformation and dynamics. Sox2 alone forms a super-stable complex near superhelical location 5 (SHL5) with similar affinity and conformation to that of naked DNA but shows elevated dynamics at suboptimal positions. Oct4 strongly favors positions near SHL5.5 and SHL6.5 and both of its DNA binding modules, $\mathrm{POU}_{S}$ or $\mathrm{POU}_{\mathrm{HD}}$, are required for stable complex formation. A ternary complex forms efficiently on canonical Sox2-Oct4 composite motifs (no spacing) near nucleosome ends but is sparse at spaced motifs and absent at internal sites. Moreover, the ability of Sox2 to fold and bend DNA plays a key role in the formation of a stable nucleosome complex and cooperative Oct4 binding. Collectively, our findings describe diverse binding modes of Sox 2 and Oct4 on nucleosomes that could guide their site selection and potential interaction with other chromatin factors in vivo.
\end{abstract}




\section{Introduction}

The genomes of eukaryotic organisms are hierarchically organized into a three-dimensional structure that plays critical roles in physiology and disease. The basic structural units of eukaryotic DNA packaging are nucleosomes, which contain $\sim 145$ base pairs of DNA wrapped nearly two times around an octamer of four core histone proteins (H2A, H2B, H3, and H4) in a left-handed spiral. ${ }^{1,2}$ The positioning of nucleosomes on genomic DNA can significantly interfere with the action of proteins called transcription factors (TFs). ${ }^{3,4}$ TFs recognize specific DNA sequences at the regulatory (promoter and enhancer) regions of genes and ensure correct patterns of gene expression. ${ }^{5}$ Nucleosomes can severely limit access of TFs to their target sites and present a strong barrier to transcription initiation. ${ }^{6,7}$ To overcome this barrier, cells dynamically modulate nucleosomes through the concerted action of DNA-binding proteins, chromatin modifying and remodeling enzymes, and the RNA Polymerase II transcriptional machinery. ${ }^{3,8}$

Unlike many TFs, a subset termed "pioneer" TFs (pTFs) can efficiently bind their recognition motifs on DNA embedded in nucleosomes at certain genomic regions. ${ }^{9,} 10$ Pioneer TF binding can lead to opening of silent chromatin regions and trigger diverse transcriptional programs. ${ }^{11-13}$ Genome-wide studies support an intricate mechanism of pTF-induced chromatin opening that involves multiple events and the action of other chromatin factors. ${ }^{14-16}$ Recent high-resolution structural studies show how certain pTFs engage with nucleosomes and possibly perturb the structure of chromatin. ${ }^{17,}{ }^{18}$ The current consensus model is that pTFs partially unwrap nucleosomal DNA and enable other TFs to bind and unravel nucleosomes, with the help of chromatin remodelers and modifiers, thus promoting transcription. ${ }^{12,19}$ Still, mechanistic details on how pTFs alter the conformation and packaging of nucleosomes, and if they do so directly or by modulating the activity of proteins that modify and reposition nucleosomes, remain elusive.

Pioneer TFs are represented by FoxA, p53, GATA, and the pluripotency factors Sox2, Oct4, and $\mathrm{KIf4}$, which are known to play critical roles in development, differentiation, and cell reprogramming. ${ }^{13}$, 20-23 These proteins can be amplified, mutated or mis-regulated in cancer and neurological diseases and their aberrant activation or repression can disrupt the architecture of chromatin and rewire gene networks. ${ }^{24-27}$ In vitro biochemical surveys as well as in vivo genetic studies have uncovered many structurally distinct TFs capable of binding to nucleosomes at different positions and with a range of affinities. $^{21-23,28}$ TFs with pioneering activity, the so-called nucleosome displacing factors (NDFs), have also been described in budding yeast. ${ }^{29}$ Despite their diverse structures, many pTFs seem to share similar features. They typically recognize DNA motifs via short a-helices in the major groove, which are compatible with nucleosome topology and, thus, are not be expected to significantly alter nucleosome structure. ${ }^{23} \mathrm{~A}$ well-studied representative of this group is human FoxA, which structurally resembles the linker histone $\mathrm{H} 1 .^{30}$ FoxA binds preferentially to its motif near the nucleosome dyad ${ }^{11}$ and maintains local chromatin accessible by competitively displacing $\mathrm{H} 1 .^{31}$ Other modes of DNA 
recognition by pTFs include HMG box domains, which bind in the DNA minor groove and induce a large helical bending. ${ }^{32}$ HMG proteins, including Sox2, are believed to favor nucleosome binding by exploiting the pre-bent conformation of DNA. ${ }^{23,33}$

How do pTFs recognize nucleosomes and target select sites in the genome? In the nucleosome, DNA curvature and histone contacts modify the physico-chemical properties and accessibility of the DNA helix. DNA bending leads to widening of the major and minor groove facing outward and narrowing of the grooves facing in towards the histone core. ${ }^{1}$ Multiple studies suggest that pTFs prefer the solvent-exposed, outside surface and disfavor the buried, inner surface of nucleosomal DNA. ${ }^{17,}$ 18, 28, 34 Direct structural insights into pTF-nucleosome recognition come from a limited number of highresolution studies of Sox2 alone or with its functional partner Oct4 obtained by cryo-electron microscopy (cryo-EM). ${ }^{17,18}$ Sox2 and Oct4 are pTFs that regulate cell-fate decisions ${ }^{35}$ and are known to engage with silent chromatin in embryonic stem cells (ESCs) and during induced pluripotent stem cell (iPSC) generation. ${ }^{33,36,37}$ They can bind synergistically and interact directly on adjacent sites in vitro $^{38}$ and colocalize on target genes in vivo. ${ }^{39-41}$ To perform their synergistic role, Sox 2 and Oct4 cobind on adjacent (canonical) or closely spaced motifs, where the spacing determines their interactions and degree of cooperativity. ${ }^{42,43}$ The Sox2 HMG domain folds into an L-shaped structure and binds DNA in the minor groove, severely bending and unwinding the helix. ${ }^{42,}{ }^{44}$ Oct4 recognizes a longer octameric motif using a bi-partite domain comprised of a POU-specific (POU $)$ and a POUhomeodomain $\left(\mathrm{POU}_{\mathrm{HD}}\right)$ subunit connected by a flexible linker. ${ }^{42,44,45}$ On the canonical composite motif, found in the Nanog promoter, protein-protein contacts and shape complementarity occur between the Sox $2 \mathrm{HMG} \alpha 3$ helix and the $\mathrm{POU}_{\mathrm{S}}$ subunit. ${ }^{43}$ On the 3 base-pair spaced composite motif, represented by the Fibroblast growth factor 4 (Fgf4) enhancer, contacts are formed between the HMG C-terminal tail and $\mathrm{POU}_{S}$ and confer weaker cooperativity. ${ }^{42}$ The HMG domain ends up on the same face of the DNA helix as POU on Nanog (canonical) sites and as POU $\mathrm{HD}_{\mathrm{S}}$ on Fgf4 sites. This configuration predisposes the canonical motif, where both HMG and $\mathrm{POU}_{S}$ can bind accessible surfaces, for optimal synergism on nucleosomes.

The cryo-EM studies of Sox2 bound to nucleosomes, with or without Oct4 on a canonical motif, show that the two pTFs bind at adjacent solvent-exposed sites and perturb nucleosome structure to a variable extent. ${ }^{17,}{ }^{18}$ Binding of Sox2 at an internal site near superhelical location 2 (SHL2) locally deforms DNA and can cause unwrapping of the adjacent gyre. ${ }^{18}$ In the presence of Oct4 at a less internal site ( SHL5), Sox2 induces large DNA bending similar to its naked DNA-bound state without unwrapping from the histone core. ${ }^{17}$ Binding of Sox2 and Oct4 near the DNA entry and exit points ( SHL6) severely distorts the DNA helix, which could displace $\mathrm{H} 1$ and affect inter-nucleosome packing. ${ }^{17}$ In the tertiary complexes, Oct4 engages nucleosomal DNA with only one of its DNA-binding modules $\left(\mathrm{POU}_{\mathrm{S}}\right)$ at its solvent-exposed half-site, while the half-site for $\mathrm{PO} \mathrm{U}_{\mathrm{HD}}$ remains occluded by the histone core. ${ }^{17}$ The $\mathrm{POU}_{\mathrm{HD}}$ subunit is not observed and, as suggested by molecular dynamics (MD) 
simulations, ${ }^{46,47}$ may adopt other configurations and transiently interact with both DNA and histones. Although these studies have provided crucial insights in pTF-nucleosome recognition, a systematic analysis of the binding affinity, protein conformation, and synergism of Sox2 and Oct4 as a function of nucleosome position, composite motif and nucleosomal DNA sequence is needed. Also, the dynamic nature of Sox2 and Oct4 binding modes and concurrent nucleosome perturbations cannot be adequately visualized using X-ray crystallography and cryo-EM techniques. We propose to address these challenges by using state-of-the-art solution NMR spectroscopy methods tailored for large biomolecules (methyl TROSY) ${ }^{48,49}$ to interrogate pTF conformation and dynamics as well as pTFinduced structural and dynamics changes in nucleosomes. Here, we combine traditional biochemistry, chemical probing and powerful NMR techniques to determine the binding affinities and the conformation of Sox2 and Oct4 for a range of nucleosome positions and in the context of different composite motifs. Our findings suggest that the affinity and synergistic binding of Sox 2 and Oct4 to nucleosomes correlate with solvent-exposed sites but are highly position and DNA sequence dependent and can be linked to different pTF conformation and dynamics. These binding preferences are likely guided by variations in histone-DNA contacts, DNA shape and flexibility across the nucleosome.

\section{Results}

\section{Design of nucleosome constructs with Sox2 and Oct4 composite binding sites}

In this study, we aimed to determine the binding affinity of Sox2 and Oct4 to nucleosome core particles (NCPs) and its modulation by nucleosome position and composite motif sequence. Towards this, we prepared double fluorophore-labeled (5'-FAM and 5'-Cy3) mono-nucleosomes with the Sox2-Oct4 composite site located at variable positions along a 145 base-pair fragment with the Widom 601 nucleosome positioning sequence (Figure 1A, Table S1). ${ }^{50}$ The original 601 sequence was modified on one end $\left(601^{*}\right)$ to replace a degenerate Sox2-binding site in nucleosomes (see Table S1). The Sox2-Oct4 composite site was derived from the regulatory enhancer region of the mouse Fgf4 $(\mathrm{mFgf} 4)^{51}$ and the proximal promoter region of the mouse Nanog (mNanog) ${ }^{39}$ genes involved in embryonic development (Figure 1A, B). The mFgf4 motif contains a 3 base-pair spacer between the Sox2 (italicized) and Oct4 (underlined) binding sites (5'CTTTGTTTGGATGCTAAT), while the mNanog motif contains no spacing between the two binding sites (5'CATTGTAATGCAAAA) (Figure 1A, B). The composite motifs were typically placed in a way to ensure the DNA minor groove of the Sox2 site was facing outward and away from the histone core and the second DNA gyre, oriented in the 5'-to-3' direction on the FAM-labeled strand (NCP 2R, 23R, 54R, 55R, and 65R) or the Cy3-labeled strand (NCP 0, 52, and 62) (Figure 1A). The naming of the NCP (DNA) constructs reflects the location of the central G-C base-pair within the Sox2 motif (5'CT/ATT $\underline{G}$ TT/A) on the $601^{*}$ sequence and the subscript identifies the mFgf4 $(F)$ or mNanog $(N)$ motif. The motifs were inserted in the forward or reverse 
orientation at the dyad and near SHL2, 3, 5 and 6 (see Figure 1A). Several other sites were designed so that the Sox2 motif was only partially exposed (NCP 27,32 ). The $601^{*}$ sequence was used as a control. The accessibility of the Oct4 major groove binding site varied depending on the inter-motif spacing and rotational setting on the nucleosome (Figure 1A). Specifically, the POUs subunit binding site (5' ATGC) was mostly accessible in $2 R_{N}, 23 R_{N}, 32_{F}, 54 R_{N}$, and $62_{N}$, while the POU ${ }_{H D}$ subunit binding site ( $5^{\prime}$ T/AAAT/A) was mostly accessible in $0_{F}, 2 R_{F}, 23 R_{F}, 27_{N}, 52_{F}, 54 R_{F}, 55 R_{F}$, and $62_{F}$ constructs. The location of the composite motif in NCP $54 R_{N}$ and $62_{N}$ constructs was the same $\left(62_{N}\right.$ was symmetrically flipped to the + side) as in the cryo-EM structures of Sox2 and Oct4 bound to a 601-based nucleosome. ${ }^{17}$

\section{Sox2 binds distinct nucleosome positions and forms a super-stable complex at SHL5}

First, we probed the relative binding affinity of the human Sox2 HMG DNA-binding domain (DBD, residues 39-118) to nucleosomes or naked DNA using electrophoretic mobility shift assay (EMSA) (Figure 1 and Figure S1) and quantified the apparent dissociation constant $\left(\mathrm{K}_{\mathrm{d}}\right)$ at near-physiological salt concentrations (Table 1). We observed formation of a discrete super-shifted band representing the Sox2-nucleosome complex at positions 23R, 54R, 55R, and 65R and a less shifted weaker band at positions 52 and 62 (Figure 1C). Sox2 bound most tightly to NCP 54R at a distinct position near SHL5 with a slightly higher affinity for the $\mathrm{mFgf4}\left(54 \mathrm{R}_{\mathrm{F}}, \mathrm{K}_{\mathrm{d}} \sim 2.0 \pm 0.2 \mathrm{nM}\right)$ than the mNanog sequence $\left(54 \mathrm{R}_{\mathrm{N}}, \mathrm{K}_{\mathrm{d}} \sim 6.4 \pm 0.3 \mathrm{nM}\right.$ ) (Figure 1D). In comparison, Sox2 binding to DNA 54R was only $\sim 2$-fold tighter than binding to NCP 54R, with $\mathrm{K}_{d}$ of $1.1 \pm 0.2 \mathrm{nM}$ and $3.0 \pm 0.4 \mathrm{nM}$ for the mFgf4 and mNanog motifs in naked DNA, respectively (Figure 1D). Shifting the composite site by one base-pair in NCP $55 \mathrm{R}_{\mathrm{F}}$ led to a detectable 4-fold decrease in binding affinity $\left(\mathrm{K}_{\mathrm{d}} \sim 8.3 \pm 1.0 \mathrm{nM}\right)$ and lower complex stability relative to NCP $54 \mathrm{R}_{\mathrm{F}}$, as indicated by more pronounced smearing between the free and NCPbound state (Figure 1C). Translating the composite site to a more internal position near SHL2 in NCP 23R attenuated Sox2 binding at the mNanog motif $\left(\mathrm{K}_{d} \sim 12.7 \pm 1.3 \mathrm{nM}\right)$ and completely abolished the discrete complex at the mFgf4 motif (Table 1). Surprisingly, moving the composite motif by one helical turn and closer to the nucleosome edge (entry/exit DNA) in NCP 65 $\mathrm{R}_{\mathrm{F}}$, where transient DNA unwrapping occurs, ${ }^{52}$ diminished the affinity and stability of the complex $\left(\mathrm{K}_{\mathrm{d}} \sim 12.4 \pm 1.2 \mathrm{nM}\right)$. Alternatively, inverting the orientation of the Sox2 motif while preserving its position on DNA in NCP $52_{\mathrm{F}}$ as compared to NCP $54 \mathrm{R}_{\mathrm{F}}$ also led to a sizeable decrease in binding $\left(\mathrm{K}_{\mathrm{d}} \sim 11.1 \pm 1.4 \mathrm{nM}\right)$ and a less shifted band for the complex, possibly signifying a lower degree of DNA deformation. The binding of Sox2 to NCP 62 ( $\mathrm{K}_{\mathrm{d}} \sim 45 \pm 7 \mathrm{nM}$ for mFgf4 and $\mathrm{K}_{\mathrm{d}} \sim 38 \pm 5 \mathrm{nM}$ mNanog) was similarly weakened relative to the inverted site in NCP $65 \mathrm{R}_{\mathrm{F}}$. Other internal nucleosome positions displayed mostly nonspecific binding that was indistinguishable from the control $601^{*}$ nucleosome $\left(\mathrm{K}_{d} \sim 41 \pm 4 \mathrm{nM}\right.$ ) (Figure $1 \mathrm{C}$, Table 1). Constructs with the Sox2 motifs placed in either orientation at the dyad, where it is 
largely accessible, showed only marginally stronger binding affinities (i.e. $\mathrm{K}_{d} \sim 29 \pm 3 \mathrm{nM}$ for NCP $0_{\mathrm{F}}$ ) than the control sequence and substantially weaker affinity than for NCP 54R constructs. The affinities for weak or non-specific binding sites agreed well with previously published fluorescence polarization measurements of Sox2 binding to a similar 601-based nucleosome ( $\left.\mathrm{K}_{d} \sim 20-60 \mathrm{nM}\right) .{ }^{17}$ At the same time, nanomolar affinities $\left(\mathrm{K}_{\mathrm{d}} \sim 0.3-1.4 \mathrm{nM}\right)$ comparable to those of NCP $54 \mathrm{R}_{\mathrm{F}}$ have been previously reported for the full-length human Sox2 protein binding to a Lin28B-based nucleosome under low salt conditions. ${ }^{33}$ Moreover, while the binding affinities of Sox2 to nucleosomes recorded here were highly sensitive to the superhelical position $\left(K_{d} \sim 2-50 \mathrm{nM}\right)$ for solvent-exposed motifs, the affinities for the corresponding naked DNA constructs were much less variable $\left(\mathrm{K}_{\mathrm{d}} \sim 1-4 \mathrm{nM}\right)$. Our findings point to a strong position and sequence preference of Sox2 association with nucleosomes, which is likely guided by the nucleosome shape and histone-DNA contacts.

\section{Oct4 forms a stable lower-affinity nucleosome complex near SHL5.5 and SHL6.5}

Next, we used EMSA to interrogate the binding of the Oct4 bipartite DBD, which consists of a POU and $\mathrm{POU}_{\mathrm{HD}}$ subunit connected by a long flexible linker, to DNA and nucleosomes (Table 1). In agreement with prior studies, ${ }^{17,46,53}$ Oct4 alone formed a discrete stable complex only with nucleosomes that contained the binding site near SHL5.5 and SHL6.5, including NCP $54 \mathrm{R}_{\mathrm{F}}, 55 \mathrm{R}_{\mathrm{F}}$, $54 R_{N}$ and $62_{N}$ (Figure 2 and Figure S1). Two super-shifted bands were observed with NCP 55R $54 R_{N}$, and $62_{N}$ at low ratios of Oct4 to NCP (Figure $2 A$ and Figure S1). This suggests that Oct4 may interact with more than one site on these constructs or utilize distinct modes of binding to its cognate motif that yield different gel migration. In addition, we note that Oct4 can bind stably to nucleosomes, where the $\mathrm{POU}_{S}$ motif is exposed and $P O U_{H D}$ motif occluded (NCP $54 R_{N}$ and $62_{N}$ ) and vice versa (NCP 54R $\mathrm{R}_{\mathrm{F}}$ and $55 \mathrm{R}_{\mathrm{F}}$ ) (Figure 2A, C). This behavior could stem from the potential of either Oct4 subunit to associate independently with DNA (Figure S2). We also observed a small amount of similarly super-shifted bands for NCP $52_{\mathrm{F}}$ and $62_{\mathrm{F}}$, which disappeared at high Oct4 ratios, likely due to low complex stability and non-specific competition (Figure 2B). Quantitative analysis of the EMSA data revealed that the high-affinity binding mode of Oct4 to nucleosomes was substantially weaker than that of Sox2 (Table 1). The association of Oct4 was slightly stronger with NCP $62_{\mathrm{N}}\left(\mathrm{K}_{\mathrm{d}} \sim 110 \pm 10 \mathrm{nM}\right)$ and $55 \mathrm{R}_{\mathrm{F}}\left(\mathrm{K}_{\mathrm{d}} \sim 110 \pm 10 \mathrm{nM}\right)$ as compared to NCP 54R $\left(\mathrm{K}_{d} \sim 240 \pm 30 \mathrm{nM}\right)$ and 54R $\left(\mathrm{K}_{d} \sim 250 \pm 20\right.$ $\mathrm{nM})$. By contrast, association of Sox2 with NCP $54 \mathrm{R}_{\mathrm{F}}$ and $54 \mathrm{R}_{\mathrm{N}}$ was roughly 100 -fold and 40 -fold tighter, respectively. Moreover, Oct4 binding to DNA comprising the mFgf4 $\left(\mathrm{K}_{\mathrm{d}} 32 \pm 3 \mathrm{nM}\right)$ or mNanog $\left(\mathrm{K}_{\mathrm{d}} 38 \pm 4 \mathrm{nM}\right)$ motifs was significantly tighter than binding to the respective NCPs. All other nucleosomes formed a relatively unstable complex with Oct4 with a substantially lower affinity comparable to the control sequence (Figure 2 and Figure S1). 
To dissect the ability of each Oct4 module to interact independently with nucleosomes, we also probed the binding of truncated protein constructs corresponding to the $\mathrm{POU}_{S}$ or $\mathrm{POU} \mathrm{HD}_{\mathrm{HD}}$ subunits to nucleosomes (Figure S2). Unlike with the full Oct4 DBD, binding of $\mathrm{POU}_{S}$ or $\mathrm{POU}_{\mathrm{HD}}$ to NCP 54R $\mathrm{R}_{\mathrm{F}}$ and $54 \mathrm{R}_{N}$ did not result in a distinct band but instead a super-shifted smear. Also, POU $U_{S}$ appeared to be saturating NCP $54 \mathrm{R}_{\mathrm{F}}$ at lower concentrations than $\mathrm{POU} \mathrm{UD}_{\mathrm{HD}}$. This was unexpected, as the POU $\mathrm{U}_{\mathrm{S}}$ half-site in $\mathrm{mFgf4}$ is predicted to be obstructed by histones, while the $\mathrm{POU}_{\mathrm{HD}}$ half-site should remain accessible (Figure 2C). This signifies that $\mathrm{POU}_{\mathrm{S}}$ might be interacting with a different sequence within the mFgf4 motif in NCP $54 R_{F}$ (and 55R ). Lastly, simultaneous addition of POU $U_{S}$ and POU $\mathrm{HD}_{\mathrm{HD}}$ to either NCP 54R or $54 \mathrm{R}_{\mathrm{N}}$ did not recapitulate the binding profile of the full Oct4 DBD. In fact, it appeared to inhibit binding relative to each truncated protein alone, which could imply possible competition or aggregation. Thus, our results show that the linked configuration of the $\mathrm{POU}_{\mathrm{S}}$ and $\mathrm{POU} \mathrm{HD}_{\mathrm{H}}$ sub-domains within the Oct4 DBD is required for high-affinity binding at SHL5.5 and SHL6.5. These findings are in line with recent reports showing diminished Oct4-nucleosome binding with alterations in the linker region. ${ }^{54}$

\section{Sox2-Oct4 synergism is enhanced on canonical motifs near nucleosome edges}

We further employed EMSA to monitor how nucleosome position affects the formation of the Sox2Oct4-NCP ternary complex and the synergistic action of Sox2 and Oct4 (Figure 2A, B and Figure S3). Most prominently, we observed a clear stabilization of Sox2 or Oct4 binding to the nucleosome in the presence of the other protein for NCP $54 \mathrm{R}_{\mathrm{N}}$ and, more strongly, to NCP $62_{N}$ containing the canonical mNanog motif (Figure 2A, B). The ternary complex appeared as a super-shifted band migrating slower than the binary complexes in NCP $54 \mathrm{R}_{\mathrm{N}}$ or as an overall more retarded band in NCP $62_{\mathrm{N}}$. The different migration pattern for NCP $62_{\mathrm{N}}$ could be due to faster binding kinetics and/or different conformations with similar electrophoretic mobilities. Stable formation of the ternary complex was not surprising in mNanog constructs, where the orientation of the Sox2 HMG and Oct4 POU sites made them accessible and enabled direct interaction between the two proteins. However, the ternary complex could not be detected on a more internal position in NCP $23 R_{N}$, where both the Sox2 and Oct4 POU sites were still solvent exposed. This suggests that factors other than solvent accessibility of nucleosomal DNA influence the cooperative binding of the two proteins.

By contrast, the ternary complex was scarce or entirely absent on nucleosomes containing the spaced mFgf4 motif, consistent with the $\mathrm{POU}_{\mathrm{S}}$ half-site being occluded by the histone octamer (Figure 2C). For NCP $54 R_{F}$ and $55 R_{F}$, we detected two resolved bands in the presence of both proteins, which corresponded to the binary Sox2-NCP and Oct4-NCP species (Figure 2A, B). The Oct4-NCP signal disappeared as the concentration of Sox2 was increased, possibly with non-specific binding or allosteric interactions displacing Oct4 from the nucleosome. Interestingly, for NCP $62_{F}$ that does not associate stably with either Sox 2 or Oct4, we observed a small but detectable amount of a new super- 
shifted band consistent with a ternary Sox2-Oct4-NCP complex. This band was not detectable in NCP $52_{F}$, where the mFgf4 motif is placed in a similar rotational setting as in $\mathrm{NCP} 62_{\mathrm{F}}$ but translated internally by one helical turn. Finally, the ternary complex was not observed near the dyad (NCP 0 , $2 \mathrm{R}$ ) or at an internal site (NCP 27) containing either the mFgf4 or mNanog motif or in the control sequence (Figure S3). These results suggest that the ternary complex is disfavored at internal positions, regardless of the motif sequence or spacing between the Sox 2 and Oct4 sites. However, it can be efficiently formed at canonical composite sites (mNanog) near SHL5 and SHL6 or transiently established at spaced composite sites (mFgf4) incorporated at nucleosome ends, possibly due to spontaneous DNA unwrapping.

\section{Sox2 binding at SHL5 mimics DNA-bound state but is dynamic at suboptimal positions}

Next, to gain insight into the conformation of various Sox2-NCP complexes, including the super-stable complex at SHL5, we employed chemical and enzymatic probing coupled with NMR experiments tailored for super-large biomolecules. First, we used DNasel footprinting of Sox2 and Oct4, alone or together, with various NCPs and corresponding naked DNA to pinpoint the location of the bound protein, which would manifest as reduced nuclease cleavage (Figure 3 and Figure S4). First, we observed a strong footprint of Sox 2 at its cognate motif on naked DNA (any construct) as well as weaker footprints at other non-cognate sites, consistent with the non-specific binding seen by EMSA (Figure 1 and Figure S1). For nucleosomes, Sox2 binding to NCP 54R $\mathrm{R}_{\mathrm{F}}$ and $55 \mathrm{R}_{\mathrm{F}}$ also resulted in a selective DNasel footprint at the mFgf4 motif, while no reduced cleavage was detected on other sites (Figure 3A). A more pronounced footprint was observed for NCP $54 \mathrm{R}_{\mathrm{F}}$ than $55 \mathrm{R}_{\mathrm{F}}$, consistent with the higher affinity of Sox2 determined here. Oct4 binding to naked DNA generated a single footprint near its cognate motif, which was slightly enhanced with the addition of Sox2 (Figure 3A and Figure S4). A weaker reduction of DNasel cleavage near the Oct4 motif was also observed in the context of nucleosomes. A stronger footprint for NCP 55R $\mathrm{R}_{\mathrm{F}}$ again correlated with tighter Oct4 binding at that site. Weaker Oct4 binding as compared to Sox2 and high nuclease activity near the Oct4 motif at the DNA termini most likely contributed to the weaker Oct4 footprint relative to that of Sox2. By contrast, the footprint could be clearly detected for internal Oct4 motif positions in naked DNA (Figure S4). These results indicate that both Sox2 and Oct4 recognized their specific motifs on naked DNA and can bind their motifs selectively in the context of nucleosomes.

Next, we used chemical crosslinking to probe whether Sox2 binding alone induced a large deformation in nucleosomal DNA similar to those observed in its complex with naked DNA and in the ternary complex with Oct4 on nucleosomes. Towards this, we prepared an NCP $54 \mathrm{R}_{\mathrm{F}}$ construct with histone H2B harboring a cysteine mutation at Serine 53 (S53C) in a cysteine-free histone background $(\mathrm{H} 3(\mathrm{C} 110 \mathrm{~A}))$. The sulfhydryl group on the cysteine residue was chemically labeled with the photolabile crosslinker 4-azidophenacyl bromide (APB). When exposed to UV light, the APB moiety crosslinks 
with nucleosomal DNA in its proximity $(\sim 10 \AA) .{ }^{55,56}$ The H2B(S53C), when functionalized with APB on both H2B histones, has been shown to effectively crosslink to DNA (positions \pm 53 and \pm 55 , Figure $1 \mathrm{~A}$ ) on both sides of the nucleosome. ${ }^{56}$ Based on the structure of the Sox2-Oct4-NCP ternary complex, where a large DNA helical bending pulls the backbone away from $\mathrm{H} 2 \mathrm{~B}(\mathrm{~S} 53)$ by over $8 \AA$, we predicted that APB crosslinking would be suppressed upon Sox2 binding. Here, we carried out a crosslinking reaction of $\mathrm{NCP5} 4_{F} \mathrm{H} 2 \mathrm{~B}(\mathrm{~S} 53 \mathrm{C})$ in the presence or absence of Sox2 and Oct4. Nucleosomal DNA, selectively cleaved at the crosslinked sites, was visualized on both strands on a sequencing gel at base-pair resolution. In line with previous studies, we observed pronounced cleavage in free nucleosomes at position +55 and -55 on the on the Cy3-labeled and FAM-labeled DNA strand, respectively (Figure 3B). Addition of Sox2 abolished DNA cleavage at base-pair +55 (Cy3 strand) located within the mFgf4 motif but not at base-pair -55 (FAM strand) that lacks the Sox2 motif. DNA cleavage was reduced to a similar degree with Sox2 alone or in the presence of Oct4. By contrast, addition of Oct4 only to $\mathrm{NCP} 54_{\mathrm{F}} \mathrm{H} 2 \mathrm{~B}(\mathrm{~S} 53 \mathrm{C})$ did not decrease the extent of DNA cleavage as compared to the free NCP. Our data strongly suggests that Sox2 binding alone induces severe deformation of nucleosomal DNA, likely similar to that observed in Sox2-DNA and Sox2-Oct4-NCP complexes. Oct4, on the other hand, does not appear to considerably distort nucleosomal DNA near the crosslink site but may still cause DNA deformation several base-pairs away.

We also wondered if the conformation of Sox2 bound to NCP54 $F$ was similar to that of the DNA-bound state. To this end, we used solution NMR spectroscopy methods tailored for large

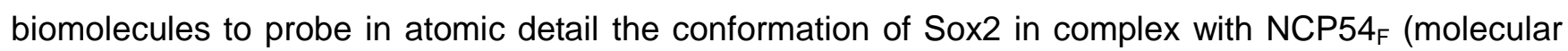
weight $(\mathrm{MW}) \sim 200 \mathrm{kDa}$ ) and other lower-affinity NCP constructs. The observation of high-MW complexes by solution-state NMR using conventional uniform isotopic labelling is typically hindered by the slow overall tumbling and fast transverse relaxation rates, leading to extreme line broadening of the resonance signals. Methyl transverse relaxation-optimized spectroscopy (TROSY)-based methods take advantage of the slowly relaxing coherences of methyl $\left({ }^{13} \mathrm{CH}_{3}\right)$ groups in large biomolecules to detect and characterize super-large protein and nucleic acid complexes with improved resolution and sensitivity. ${ }^{48,49}$ Here, we employed site-specific ${ }^{13} \mathrm{C}$-labeling of isoleucine, leucine, valine, and alanine (ILVA) methyl groups of the Sox2 HMG DNA-binding domain in a deuterated protein background combined with methyl TROSY NMR to probe Sox2 binding to nucleosomes or naked DNA. ${ }^{57}$ Sox2 HMG methyl resonance assignments for the free and DNA-bound state were obtained using $a{ }^{13} \mathrm{C}$, ${ }^{15} \mathrm{~N}$-labeled protein alone or in complex with a short (15 base-pair) DNA duplex containing the mFgf4 site $\left(s D N A_{F}\right)$. Figure $4 A$ shows a methyl ${ }^{1} \mathrm{H},{ }^{13} \mathrm{C}-\mathrm{HMQC}$ spectral overlay of Sox2 free, bound to $\mathrm{sDNA}_{\mathrm{F}}$ or bound to NCP $54 R_{F}$. Sox2 association with its cognate DNA motif causes sizeable chemical shift changes in a number of methyl sites near the protein-DNA interface (Figure 4A), which can be used as reporters of the Sox 2 conformation. We also confirmed that the complexes with short and long (145 base-pair) DNA are nearly identical (Figure S5). For comparison, Sox2 binding to a random non- 
specific short DNA (sDNA $\mathrm{ctr}_{\text {) }}$ leads to distinct chemical shift changes and significant line broadening for the respective sites (Figure S5). When examining nucleosome complexes, we found that the Sox2NCP $54 \mathrm{R}_{\mathrm{F}}$ complex resembles closely the Sox2-DNA bound state, with only small chemical shift changes observed for the NCP-bound state. Several additional weaker peaks were visible in Sox2NCP $54 R_{F}$ that overlay with peaks of the free Sox2 (i.e. V5, A11, V14, L45), which could be due to incomplete saturation or alternative bound conformations of Sox2. Our findings that the Sox2 conformation is similar for specific DNA and NCP $54 \mathrm{R}_{\mathrm{F}}$ complexes is consistent with the similar high affinities for these constructs obtained by EMSA and the nucleosomal DNA deformation observed in crosslinking experiments.

We further investigated the complex between Sox2 and weaker binding nucleosomes, in the presence or absence of Oct4. For NCP $62_{\mathrm{F}}$ and $62_{\mathrm{N}}$, a number of residues in the $1: 1$ complex with Sox2 displayed significant line broadening and multiple corresponding peaks residing between the chemical shift of the Sox2 free and DNA-bound state (Figure 4B). For NCP 27 F, which binds even less tightly to Sox2, we observed a similar behavior. However, the peaks were shifted closer to the protein free state in the 1:1 complex and moved only slightly towards to the DNA-bound state with excess of nucleosome (Figure 4B, Figure S5). These findings imply two scenarios: (i) Sox2 is only partially saturated and undergoes intermediate-to-fast exchange between the free and DNA-bound state on the NMR timescale and (ii) Sox2 adopts two or more distinct conformations that resemble the free state while associated with weaker binding sites on nucleosomes. Since these spectra resemble the spectrum of Sox2 bound to a non-specific DNA at saturating concentrations (Figure S5), the second scenario is likely active. Titration of Oct4 to the Sox2-NCP $62_{N}$ sample, which based on EMSA results is expected to form is a stable ternary complex, shifted the resonance peaks closer to the DNA-bound state. This pointed to an increased population of the NCP-bound state of Sox2. However, even addition of excess Oct4 and nucleosome did not fully reproduce the spectrum observed for Sox2-DNA or $-\mathrm{NCP} 54 \mathrm{R}_{\mathrm{F}}$ and left some peaks severely broadened, indicating persistent dynamics. These results suggest that Oct4-induced stabilization of the Sox2-NCP $62_{N}$ complex is not sufficient to mimic the stable complex of Sox 2 with NCP $54 R_{F}$ or with naked DNA.

\section{Impaired Sox2 folding and DNA bending activity inhibit nucleosome binding and Oct4 synergism}

In the cryo-EM structure of Sox2 and Oct4 with a nucleosome resembling NCP $54 \mathrm{R}_{\mathrm{N}}$, Sox2 binding entails disruption of the histone-DNA interface via a large DNA bending and insertion of the Sox2 Cterminal tail between the DNA and histone core. ${ }^{17}$ Interestingly, the Sox 2 HMG domain N- and Cterminal tails are largely disordered in the free state ${ }^{58}$ and only become folded upon DNA binding and bending, forming interactions in the DNA minor groove and with one another and helix $\alpha 3$ (Figure $5 A){ }^{42,} 44$ Thus, we wondered how altering the ability of Sox2 to bend DNA, through mutations in the 
protein $\mathrm{N}$ - and C-terminal tails, affects its ability to bind and bend nucleosomal DNA. Towards this, we engineered several single-point alanine mutations in the N-terminal (R7A), C-terminal (Y72A and Y74A), and $\alpha 1$-helix (N10A) of the Sox2 HMG domain (Figure $5 \mathrm{~A})$. R7 makes cross-strand hydrogen bonds with the nucleobase of $\mathrm{T}_{6}\left(\mathrm{O}_{2}\right)$ and $\mathrm{C}_{-5}\left(\mathrm{O}_{2}\right)$ in the minor groove of the mFgf4 motif and stacks against $Y 74$, which in turn hydrogen bonds to the sugar of $C_{-5}$ and the nucleobase of $A_{-6}(N 3)$. $Y 72$ does not directly interact with the DNA but is part of a hydrophobic core of residues (V5, H65, H69, and Y72) that stabilizes the C-terminal tail in the folded DNA-bound state. N10 inserts in the minor groove between residues $T_{4}$ and $G_{5}$, forming hydrogen bonds with the two nucleobases and thymine sugar. Since mutation at that position has been shown to reduce DNA bending, ${ }^{59} \mathrm{~N} 10 \mathrm{~A}$ was used as a control.

We first tested the interaction of Sox2 mutants with different nucleosome and DNA constructs using EMSA (Figure 5). Our data shows that binding of these mutants to DNA alters the electrophoretic mobility of the protein-DNA complex to a variable extent depending on the mutant identity and position of the Sox2 motif (Figure 5B). In general, migration of the mutant complexes was faster than that of the wild-type (WT) complex in the order N10A > Y74A R7A $>$ Y72A $>$ WT for mFgf4 and N10A > Y74A > Y72A R7A > WT for mNanog. This was evident when the Sox2 motif was located in the center of the DNA sequence (DNA $2 R_{F}$ and $2 R_{N}$, Figure $5 B$ ). DNA bending is expected to yield slower overall diffusion at the center rather than ends of the long duplex. Interestingly, binding of WT Sox2 appeared to generate an overall smaller bent for the mNanog than the mFgf4 site (Figure 5B). Moreover, the R7A mutant impaired DNA bending to a lesser extent at the $\mathrm{mNanog}$ than $\mathrm{mFgf} 4$ site, although the base-pairs that interact directly with the arginine sidechain are unchanged. The apparent DNA binding affinities for most Sox2 mutants were not substantially affected $\left(\mathrm{K}_{\mathrm{d}} \sim 3.3 \pm 0.5 \mathrm{nM}\right.$ for WT versus $4.4 \pm 0.8 \mathrm{nM}$ for R7A, $3.5 \pm 0.6 \mathrm{nM}$ for $\mathrm{Y} 72 \mathrm{~A}$, and $5.6 \pm 1.1 \mathrm{nM}$ for Y74A for mFgf4), except for N10A ( $\left.\mathrm{K}_{d} \sim 19 \pm 4 \mathrm{nM}\right)$. However, the fraction of non-specific complexes was relatively increased in Sox 2 mutants versus WT, indicating that the affinity for the cognate site was reduced.

For nucleosomes, we could not reliably assess the effect of Sox2 mutations or motif sequence on DNA bending. Association of Sox2 mutants with nucleosomes, however, showed distinct effects on the protein binding affinity and complex stability. For NCP 54R $\mathrm{R}_{\mathrm{F}}$ harboring the $\mathrm{mFgf} 4$ motif, the specific complex was largely abolished by R7A $\left(\mathrm{K}_{d} \sim 23 \pm 3 \mathrm{nM}\right)$ and, especially, N10A $\left(\mathrm{K}_{d} \sim 37 \pm 5 \mathrm{nM}\right)$ and visibly destabilized by the Y72A $\left(\mathrm{K}_{d} \sim 9.1 \pm 1.0 \mathrm{nM}\right)$ and $\mathrm{Y} 74 \mathrm{~A}\left(\mathrm{~K}_{d} \sim 5.5 \pm 0.7 \mathrm{nM}\right)$ mutants (Figure $5 \mathrm{C})$. The effect of Sox2 mutations was even more dramatic when the mFgf4 motif was shifted by one base-pair in NCP $55 R_{F}$ and a discrete band for the specific complex could no longer be detected (Figure 5C). By contrast, Sox2 mutants had a lesser impact on binding to the mNanog motif on nucleosomes (Figure $5 \mathrm{C}$ ). For NCP $54 \mathrm{R}_{\mathrm{N}}$, the specific complex could still be observed with all mutants (except for N10A), with small differences for R7A and Y72A. The impact of these mutations was less 
pronounced for the more internal position near SHL2 in NCP $23 \mathrm{R}_{\mathrm{N}}$. In addition, weaker and nonspecific binding was not substantially affected by the mutations. This data indicates that Sox2 mutations that reduce DNA bending, presumably by loss of direct contacts and/or proper Sox 2 folding, also decrease the stability of the Sox2-nucleosome complex in a sequence-dependent manner. Moreover, the higher impact of the R7A mutation on DNA bending with mFgf4 than mNanog correlates with a larger decrease in stability of mFgf4-containing nucleosome complex. This suggests that the ability of Sox2 to optimally bend DNA motifs is important for the formation of a stable nucleosome complex.

At the same time, we observed that the Sox2-Oct4-NCP ternary complex on Nanog motifs (NCP $54 R_{N}$ and $62_{N}$ ) was significantly depleted by Sox2 mutants that displayed small changes in nucleosome binding affinity alone (Figure 5D). Importantly, none of these mutations are found at the interface between Sox2 HMG and Oct4 $\mathrm{POU}_{S}$ or involved in direct protein-protein contacts on the Nanog motif. Sox2-Oct4 synergism on naked DNA containing the mNanog motif was also negatively impacted by the mutants (Figure S6). As a result of extensive signal overlap and smearing, we could not precisely quantify the decrease in cooperativity on nucleosomes. It is possible that the Sox2 Cterminal tyrosine mutations destabilize the folded protein conformation and alter the orientation or dynamics of HMG $\alpha 3$-helix that forms interactions with $\mathrm{POU}_{\mathrm{S}}$, which could affect the geometry at the Sox2-Oct4 interface.

To determine whether Sox2 folding is affected by mutations in C-terminal tyrosines, we assessed the effect of the Y72A mutant on the conformation and dynamics of Sox2 in complex with DNA by NMR. We observed large chemical shift perturbations and/or enhanced line broadening of protein backbone amides and side-chain methyl groups near the mutations cite on the C-terminal tail (i.e. H69-K79), $\alpha 3$-helix (i.e. L61-E68) and at the N-terminal tail contacting Y72 (i.e. V5, K6) (Figure 5E and Figure S7). These signified pronounced changes in the conformation and dynamics of the Sox2 mutant in complex with DNA. Thus, it is possible that the Y72A mutation reduces overall DNA bending by destabilizing the folded conformation of Sox2 on DNA. Together with our EMSA results, these findings establish that the impaired ability of Sox2 to properly fold and bend DNA could lead to an altered conformation on nucleosomes and negatively impact the stability of the ternary complex with Oct4.

Finally, to examine the ability of Sox2 mutants to produce a stable bent DNA conformation in the context of nucleosomes, we performed the APB crosslinking assay with NCP $54 \mathrm{R}_{\mathrm{F}} \mathrm{H} 2 \mathrm{~B}(\mathrm{~S} 53 \mathrm{C})$ and the mutant proteins (Figure S6). We detected significant DNA cleavage for R7A and N10A mutants, which was reduced by roughly $50 \%$ relative to the free NCP. Binding of $Y 72 A$ and $Y 74 A$ mutants resulted in considerably less DNA cleavage $(<20 \%)$. The addition of Oct4 did not significantly affect the cleavage profile in the presence of Sox 2 WT or mutants. These findings could be explained by variations in the binding affinities across Sox2 mutants as well as differences in the degree of DNA 
bending at the Sox2 binding site. The enhanced cleavage with R7A and N10A mutants, which show weaker affinity and do not produce a stable nucleosome complex by EMSA, could result from a larger fraction of free NCP. It is unclear whether the unstable complex reflects faster dissociation kinetics with a bent DNA conformation similar to the WT complex or less significant DNA deformation or both. Conversely, the reduced cleavage with Y72A and Y74A mutants, which retain tighter binding and form the stable complex, correlates with a highly bent DNA conformation. Further studies probing the kinetics of Sox2 binding to nucleosomes and the conformation of Sox2 mutants are required to discern between different scenarios. Overall, our mutational and NMR studies point to a key role of Sox2 HMG domain folding and coupled DNA bending in establishing a stable complex and Oct4 interactions on nucleosomes.

\section{Discussion}

It remains largely unclear how pTFs recognize nucleosomes and target only a subset of their specific motifs in silent chromatin in vivo. One possible mechanism is that they exhibit strong preferences for specific positions on the nucleosome. Thus, well-defined nucleosome positioning within the genome can help guide pTFs localization to their optimal binding sites. In this study, we find a strong dependence of the binding affinity and stable complex formation of Sox2 and Oct4 on the position and sequence of their cognate motifs on nucleosomes. We observe that motifs where the minor groove of

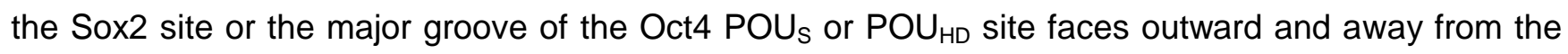
histone core are generally favored. Our findings are consistent with previous experimental and in silico studies showing preferential Sox2 and Oct4 binding to solvent-exposed sequences on nucleosomes. ${ }^{17}$, $18,23,34,46$ This is expected due to the high energetic cost of dissociating large segments of nucleosomal DNA from the histone octamer to accommodate protein binding on the inner surface, particularly at more internal positions. Additionally, unfavorable electrostatics between the positively charged pTFs and histones as well as steric and geometric constraints would further disfavor inner facing binding schemes.

While solvent accessibility plays a major role, it is not the only factor that determines the binding preference of pTFs. We find that Sox2 favors strongly only certain solvent exposed nucleosome sites. We observe a super-stable Sox2-nucleosome complex near SHL5 (NCP 54R) and somewhat less stable ones near SHL2 (NCP 23R) and SHL6 (NCP 65R). For those positions, the DNA minor groove faces outward and the Sox2 N- and C-terminal tails are oriented away from the neighboring DNA gyre. Prior high-resolution studies have captured only the Sox2-Oct4-NCP ternary complex where the pTF binding site is positioned identically as in NCP 54R. ${ }^{17}$ Here, by using gel shift, nuclease footprinting, and sensitive NMR methyl TROSY experiments, we demonstrate that Sox2 alone binds NCP 54R with high specificity and with similar affinity and conformation to that when binding to naked DNA. The affinity declines by several fold if the motif is (i) shifted by even one base 
pair (NCP 55R), (ii) translated to a similar rotational position externally to SHL6 (NCP 65R) or internally to SHL2 (NCP 23R) or (iii) reversed at the same location (NCP 52). By contrast, locations that have the Sox2 motif near the dyad, other internal positions, and certain entry/exit DNA sites in either orientation display considerably weaker affinity and, as detected by NMR, potentially alternate Sox2 conformations. Smearing of the bands observed by EMSA as well as peak broadening observed by NMR suggest that those complexes are more dynamic and may exhibit faster dissociation kinetics than complexes at optimal positions. Future quantitative studies examining the site-specific binding rates and conformational dynamics of Sox2 would shed light on kinetic and thermodynamic factors that influence nucleosome recognition.

Notably, we do not observe a stable Sox2-nucleosome complex at the dyad or multiple other solvent accessible positions. Our findings contradict previous studies showing preferential binding of Sox2 and other HMG domain proteins near the nucleosome dyad. ${ }^{28}$ The discrepancy could be due to non-specific Sox 2 complexes at the dyad, observed here and by MD simulations, ${ }^{46}$ which do not generate a dramatic DNA bend and may be more abundant in the context of different (not 601) underlying sequences. ${ }^{28}$ Indeed, we find that even non-specific association of Sox 2 with nucleosomes exhibits high apparent binding affinity $\left(\mathrm{K}_{d} \sim 25-50 \mathrm{nM}\right)$, which is several fold higher than the specific binding of Oct4 to nucleosomes. We cannot exclude that this results from a strong non-cognate Sox2 binding site on the control $601^{*}$ sequence in the context of nucleosomes. In that case, fast Sox 2 dissociation rates may preclude observation of a distinct DNasel footprint with the control NCP as the one observed with non-specific binding to the control DNA.

Why are many accessible nucleosome positions, including the dyad, disfavored by Sox2? The stability of the Sox2-nucleosome complex can be largely modulated by differences in the energetic penalty for DNA bending and disruption of histone-DNA contacts to accommodate Sox2. Structural analysis of nucleosomes shows that the DNA minor groove width and extent of helical deformation vary substantially among different sites with the same rotational setting. ${ }^{60,61}$ Additionally, mapping of position-specific histone-DNA interactions by single-molecule DNA unzipping experiments ${ }^{62}$ and steered MD simulations of DNA unwrapping ${ }^{63}$ point to sizeable variations across the nucleosome. Even though the dyad has a single DNA gyre and allows for higher minor groove accessibility, it features stronger histone-DNA interactions ${ }^{62,63}$ and smaller minor groove expansion ${ }^{61}$ than other positions. These factors and the central location of the dyad would disfavor large DNA deformations and long-range helical shifts that may accompany Sox2 binding. Similar considerations apply to other internal positions that maintain strong histone-DNA contacts. ${ }^{62,} 63$ Conversely, it may seem surprising that we observe diminished binding near the DNA entry/exit points (SHL6 to SHL7), where spontaneous DNA unwrapping occurs. However, MD simulations indicate that protein-DNA contacts are actually enhanced near SHL7 relative to the region spanning SHL5 to SHL6, which is primarily due to histone $\mathrm{H} 3 \mathrm{~N}$-terminal and $\mathrm{H} 2 \mathrm{~A}$ C-terminal tail contacts with entry/exit DNA. ${ }^{63}$ Such interactions 
could make it more difficult to distort and displace the DNA helix at the edge of nucleosomes. Both NMR studies and MD simulations have uncovered extensive dynamic interactions between histone $\mathrm{H} 3$ tails and entry/exit DNA, which can impact the binding of other chromatin factors at the DNA entry/exit points. ${ }^{64}$ In that respect, it would be important to investigate the impact of targeted histone tail truncations or modifications on the binding of Sox2 to nucleosomes.

A main finding in our study is the strong preferential binding of Sox2 near SHL5, which mimics the pTF complex with naked DNA. The ability of Sox2 to strongly bind and bend DNA at that position, displacing the helix from the histone core, could stem from the overall weaker contacts between DNA and histone globular domains near SHL5. ${ }^{63}$ Examination of nucleosome structures shows that the inner facing minor groove near the Sox2 binding site is contacted by Arginine (Arg) or Lysine (Lys) residues only from the flexible $\mathrm{H} 2 \mathrm{~A}(\mathrm{SHL} \pm 4.5)$ and $\mathrm{H} 2 \mathrm{~B}(\mathrm{SHL} \pm 5) \mathrm{N}$-terminal tails. ${ }^{61}$ By contrast, all other inner minor groove positions interact with at least one Arg belonging to the globular histone domains. ${ }^{61}$ Recognition of the compressed minor groove of nucleosomal DNA (especially AT-rich sequences) by long and positively charged Arg and Lys side chains is critical for nucleosome stability and underlies the strong nucleosome positioning potential of the 601 sequence. ${ }^{65}$ Because of the flexible nature of histone tails, ${ }^{64}$ Sox2 binding near SHL5 may not entirely abolish DNA interactions with the histone tail Arg/Lys residues but instead relocate them to nearby grooves on the same $(\mathrm{H} 2 \mathrm{~A})$ and/or adjacent (H2B) DNA gyre. Additionally, while Sox2 binding at that site causes large DNA deformation, as demonstrated by our crosslinking data and the published Sox2-Oct4-NCP structure, ${ }^{17}$ it does not unwrap or change substantially the conformation and spatial orientation of entry/exit DNA. ${ }^{17}$ This suggests that the nucleosome can accommodate Sox2 binding at SHL5 without large-scale DNA distortion and still retain critical contacts between histones and DNA at the edge of nucleosomes. Collectively, these factors could facilitate the preferential binding of Sox2 near SHL5. Alternatively, binding of Sox2 at a similar rotational setting near SHL6 or SHL2 is expected to disrupt histone core Arg/Lys contacts and directly displace histone H3/H2A (SHL6) or H4 (SHL2) tails. Therefore, the reduced Sox2 binding there as compared to SHL5 could be explained by a combination of stronger and more extensive histone contacts with DNA, which may not be easily re-established at nearby DNA.

The strong Sox2 binding that we observe near SHL2 could be aided by other factors such as DNA shape and sequence. The pre-bent conformation of DNA in nucleosomes, which creates wider outward facing minor grooves, aligns with the direction of Sox2-induced DNA bending and could predispose the association of Sox2 (and other HMG proteins) with nucleosomes. Based on analysis of diverse nucleosome structures, the SHL2 position is generally characterized with the widest minor groove, on average $\sim 2 \AA$ wider than at the dyad. ${ }^{60,61}$ This, coupled with somewhat weaker interactions between the globular histone domains and DNA at SHL2 relative to most other locations, ${ }^{17}$ could contribute to the enhanced binding at that site. A recent high-resolution study showed that Sox2 
binding at a similar position near SHL2 leads to partial unwrapping of DNA on the adjacent gyre and enhanced dynamics of entry/exit DNA. ${ }^{18}$ This could provide a mechanism whereby Sox2 binding stimulates DNA opening and initial destabilization of nucleosomes. Currently, it is unclear whether this phenomenon is common in nucleosomes or whether the in vitro selected DNA sequence in that study is inherently more flexible and prone to dissociation than the 601 or other sequences. Indeed, higher structural flexibility have been observed by MD simulations for nucleosomes containing "natural" DNA sequences derived from gene regulatory regions featuring one or more pTF binding sites. ${ }^{47}$ This could be resolved by future experiments investigating the impact of DNA sequence on Sox2-induced perturbations in nucleosomes.

We also find that the sequence of the Sox2 recognition motif plays a key role in the stability of its complex with the nucleosome. The mFgf4 motif does not form a stable complex with Sox 2 near SHL2, while the mNanog motif produces a relatively stable nucleosome complex and higher apparent affinity. Conversely, at SHL5, the mNanog motif yields lower affinity for Sox2 than the mFgf4 motif. Importantly, we uncover that Sox2 association with the mNanog motif on DNA generates smaller helical bending than with the mFgf4 motif. Since differences in the motif sequence are not expected to significantly alter specific protein-DNA interactions, this likely stems from inherent variations in DNA deformability. Sox2 binding to DNA produces a large kink from intercalation of a methionine residue at the central TpG dinucleotide step. ${ }^{42}$ It is plausible that sandwiching the central TpG step with two rigid A-tract ${ }^{66}$ segments (5'TTT and 5'TTTT, Figure 1A) in the mFgf4 sequence produces a greater DNA bent than in the mNanog sequence that lacks A-tracts (Figure 1A). Larger DNA bending of the mFgf4 sequence could, in turn, optimize Sox2 folding on DNA and thus offset the higher energetic cost of DNA deformation. This is in line with our findings that Sox2 mutations that compromise its DNA bending activity, by destabilizing protein folding (Y72A by NMR), also inhibit more strongly Sox2 binding to the mFgf4 than the mNanog motif. Together, these results imply that larger DNA deformation is required for specific recognition of mFgf4 than mNanog Sox2 motifs on nucleosomes. Moreover, it seems that distinct factors dominate Sox2 binding at different nucleosome positions. We propose that, at SHL5, disruption of histone-DNA contacts has a lower energetic cost and, thus, the direct (sequence) and indirect (shape) readout of nucleosomal DNA by Sox2 resembles more closely that of naked DNA. By contrast, at SHL2, DNA bending and dissociation from the histone core has a higher energetic penalty and, thus, Sox2 favors creation of the less bent complex on the mNanog motif. A smaller Sox2-induced DNA deformation at the SHL2 is consistent with cryo-EM structures of Sox2 bound at SHL2 $\left(5^{\prime} \text { CTTTGTG }\right)^{18}$ as compared to SHL5 $\left(5^{\prime}\right.$ CTTTGTT) ${ }^{17}$ as well as with recent MD simulations. ${ }^{67}$ This model further implies that suboptimal Sox2 binding sites on naked DNA that generate smaller bending could be preferentially bound at certain nucleosome positions.

Finally, it is possible that the strong Sox2-nucleosome complexes we observe here are further stabilized by site-specific interactions between Sox2 and histones. For example, the Sox2 HMG 
domain could potentially interact with the histone H2A-H2B dimer near SHL5, particularly with the flexible $\mathrm{H} 2 \mathrm{~A}$ and $\mathrm{H} 2 \mathrm{~B} \mathrm{~N}$-terminal tails that are found in the vicinity of SHL4 and SHL5, respectively. Also, the $\mathrm{H} 4$ and $\mathrm{H} 2 \mathrm{~B} \mathrm{~N}$-terminal tails can transiently interact with DNA near SHL2, while the H3 Nterminal and H2A C-terminal tails localize at nucleosome edges near SHL6. Future experiments probing direct interaction between Sox2 and histones and investigating the effect of targeted manipulation of histone-DNA contacts could shed light into the positional preference of Sox2 on nucleosomes.

We further reveal that the Sox2 binding partner, Oct4, also exhibits strong positional preference for the major groove near nucleosome ends (SHL5.5 and SHL6.5) and mostly non-specific binding elsewhere, consistent with previous studies. ${ }^{17,46,53}$ The high-affinity complexes feature solvent exposed half-sites for either $\mathrm{POU}_{\mathrm{S}}$ or $\mathrm{POU}_{\mathrm{HD}}$. In the canonical Sox2-Oct4 complex on naked DNA, $\mathrm{POU}_{S}$ and $\mathrm{POU}_{\mathrm{HD}}$ engage with opposite faces of the DNA helix (see Figure 1B). ${ }^{42,44}$ This configuration is incompatible with nucleosome structure (see Figure 2C). Therefore, it is likely that one Oct4 subunit recognizes its specific site, while the other binds non-specifically to other nucleosome components or samples alternative conformations. This scenario is in line with the absence of electron density for the POU $_{H D}$ subunit in cryo-EM structures ${ }^{17}$ and with recent MD simulations. ${ }^{46,47,68}$ Such flexibility and conformational exploration could be assisted by the long unstructured linker between the two Oct4 modules. The $P O U_{H D}$ accessible site $\left(\mathrm{NCP} 55 \mathrm{R}_{\mathrm{F}}\right.$ ), found only several base-pairs away from the entry/exit points, may be favored due to increased DNA propensity for unwrapping that could enable transient sampling of the $P O U_{S}-D N A$ bound state. The $P_{S}$ accessible site is more internal and recognized by Oct4 with similar affinity in either orientation (NCP $54 R_{N}$ and NCP $\left.62_{N}\right)$. This hints at an intrinsic preference for that position that could stem from optimal DNA shape or potential histone interactions. Since the truncated $\mathrm{POU}_{S}$ or $\mathrm{POU}_{\mathrm{HD}}$ domains alone do not reproduce the binding profile of the full Oct4 DBD, interactions of the flexible linker and subunit with histones or nearby DNA may contribute to the binding affinity and specificity. This is supported by MD simulations showing that the Oct4 DBD adopts diverse configurations on nucleosomes engaging with both DNA and histones. ${ }^{46,47}$, ${ }^{68}$ Specifically, depending on the protein orientation, two distinct modes were captured in silico when $\mathrm{POU}_{\mathrm{HD}}$ was bound near SHL5.5: one where $\mathrm{POU}_{\mathrm{S}}$ interacts with DNA from the adjacent gyre near SHL2 and another where $\mathrm{POU}_{S}$ contacts the acidic patch of the histone $\mathrm{H} 2 \mathrm{~A}-\mathrm{H} 2 \mathrm{~B}$ dimer. ${ }^{46}$ Such alternative binding modes could explain our experimental findings that Oct4 largely favors nucleosome end positions.

Moreover, we find that the synergism of Sox2 and Oct4 is highly context dependent, with both nucleosome position and spacing between motifs playing a role. The relatively weak binding of Sox 2 to the mNanog motif at SHL6 (NCP 62N) is greatly enhanced in the presence of Oct4. This is demonstrated by the discrete ternary complex observed by EMSA and stabilization of the Sox2 bound state observed by NMR. There, Oct4 alone associates with high affinity and the POU site is optimally 
accessible and adjacent to the Sox2 HMG site, allowing for unobstructed protein-protein interaction. As seen in the corresponding cryo-EM structure, ${ }^{17}$ this complex shows a large Sox2-induced DNA bending, which profoundly alters the orientation of the linker DNA and may disrupt its interaction with histone tails (especially H3). While Oct4 alone binds stably at that position, the presence of Sox2 would be necessary to elicit the large DNA bending. This could have impact on inter-nucleosome packing or make histone tails more accessible for readout and enzymatic modification. By contrast, cooperative Sox2-Oct4 binding is scarce on the mFgf4 motif near SHL6 (NCP 62 $\mathrm{F}$ ), where the POU site is 3 base-pairs removed from the HMG site and occluded by histones. The minor ternary complex detected by EMSA could result from transient unwrapping of entry/exit DNA and accommodation of Oct4 as in the DNA-bound state or an alternative Oct4 conformation. The ternary complex could also be observed at the high-affinity Sox2 site near SHL5 and, likewise, only on the mNanog motif (NCP $54 \mathrm{R}_{\mathrm{N}}$ ). Although we do not observe strong Oct4-mediated stimulation of Sox2 binding at that position, Sox2 folding and DNA bending could be potentially optimized via interactions with POUs. By contrast, Oct4 bound to NCP $54 \mathrm{R}_{\mathrm{F}}$ and $55 \mathrm{R}_{\mathrm{F}}$ containing the mFgf4 motif is displaced by excess Sox2, which indicates that Sox2 competes for the same site or allosterically inhibits Oct4 binding at a nonoverlapping site. Importantly, the ternary complex is not observed at the dyad or internal positions containing the mNanog motif, including the higher-affinity Sox2 site at SHL2 (NCP 23R $\mathrm{R}_{\mathrm{N}}$ ). The presence of histones tails and more extensive histone-DNA interactions may preclude an optimal geometry of Sox2-Oct4 binding at more internal positions. In general, our findings agree with prior biochemical and single-molecule Forster resonance energy transfer (smFRET) studies showing that Sox2 and Oct4 bind cooperatively at end-positioned sites on nucleosomes but that this effect is attenuated or absent at the dyad and internal sites. ${ }^{17,69}$ However, it is plausible that Sox2-Oct4 synergism is augmented in the context of nucleosomes that incorporate less positioning DNA sequences or destabilizing histone mutants and variants.

Lastly, we observe that Sox2-nucleosome interactions and synergism with Oct4 can be inhibited by mutations that impair the folding of the Sox2 $\mathrm{N}$ - and C-terminal tail, which is coupled to DNA binding. These findings provide mechanistic insight into how the folding and stability of the Sox2 HMG domain affects its ability to bind and deform DNA on nucleosomes. We further propose that, because of the prohibitively high energetic cost for DNA bending, the Sox2 HMG domain is unable to fold properly at most internal positions and establish a stable complex (on the consensus motif). Indeed, for more weakly binding NCP constructs, we observe by NMR that multiple Sox2 signals are shifted towards the free state or are severely broadened, similar to non-specific DNA binding. These findings are consistent with Sox2 sampling different conformations while bound to nucleosomes. However, since Sox2 folding and DNA bending depend on the DNA sequence, certain motifs might still be favored at internal positions (similar to mNanog at SHL2). Improper folding or conformational dynamics in the C-terminal tail and $\alpha 3$ helix, which we observe by NMR for the Y72A mutation, may 
also inhibit direct interactions with Oct4 $\mathrm{POU}_{\mathrm{S}}$. Importantly, this could have broader implications for the ability of other HMG-containing proteins to bind the nucleosome and synergize with co-factors.

In summary, our findings demonstrate that pTFs Sox2 and Oct4 have optimal binding modes to nucleosomes that coincide with distinct solvent accessible positions and DNA sequences. The highaffinity nucleosome binding modes of Sox2 and Oct4 may be realized by optimal nucleosome positioning and guide pTF site selection in the cell. They might be further modulated by nucleosome composition (i.e. histone variants and modifications) and co-factor binding for more targeted chromatin localization and different functions. Extensive non-specific nucleosome binding, especially for Sox2, could also enhance pTFs chromatin association even when their cognate motifs are occluded or absent. Moreover, these diverse binding modes could facilitate the engagement of other TFs or affect the activity of chromatin enzymes and, thereby, promote chromatin opening and transcription.

\section{Materials and Methods}

\section{Protein constructs and preparation}

The human Sox2 HMG DNA-binding domain (39-118) was amplified by PCR from a modified pSpeedET plasmid ${ }^{70}$ and inserted into a modified pET15 plasmid ${ }^{71}$ containing an N-terminal (6X)Histidine (His) tag and a $3 \mathrm{C}$ protease cleavage site using standard protocols. Sox2 single alanine mutations (R7A, N10A, F54A, Y72A, Y74A) were generated using standard mutagenesis protocols. The Oct4 DBD (133-296), POU $\mathrm{S}_{\mathrm{S}}$ domain (133-228), and $\mathrm{POU}_{\mathrm{HD}}$ domain (229-296) were similarly inserted into a modified pET15 plasmid ${ }^{70,71}$ containing an N-terminal (8X)-His tag, followed by an MBP tag and $3 \mathrm{C}$ protease cleavage site. All original plasmids were obtained from the DNASU plasmid repository and the $3 \mathrm{C}$ protease site was inserted in house. All DNA oligonucleotides used for plasmid modification and mutagenesis were obtained from IDT, Inc. (Coralville, IA). For large-scale protein expression, plasmids were transformed into BL21(DE3) cells and grown in TB medium with $100 \mathrm{mg} / \mathrm{L}$ carbenicillin (for non-isotopically labeled protein) at $37^{\circ} \mathrm{C}$ with shaking until a density of $\mathrm{OD}_{600} \sim 0.6$. Protein expression was induced with $0.5 \mathrm{mM}$ IPTG and cells grown for 4 hours at $37^{\circ} \mathrm{C}$ for Sox 2 and 16-18 hours at $18^{\circ} \mathrm{C}$ for Oct4. For uniform ${ }^{15} \mathrm{~N}$ or ${ }^{15} \mathrm{~N},{ }^{13} \mathrm{C}$ isotopic labeling, cells were grown in $\mathrm{M} 9$ Minimal media supplied with ${ }^{15} \mathrm{~N}-\mathrm{NH}_{4} \mathrm{Cl}(1 \mathrm{~g} / \mathrm{L})$ and ${ }^{13} \mathrm{C}$-D-glucose $(2 \mathrm{~g} / \mathrm{L})$. For unform ${ }^{2} \mathrm{H},{ }^{15} \mathrm{~N}$-labeling with site-specific Ile $\delta 1-\left[{ }^{13} \mathrm{CH}_{3}\right]$, Leu,Val- $\left[{ }^{13} \mathrm{CH}_{3},{ }^{12} \mathrm{CD}_{3}\right]$, Ala- $\left[{ }^{13} \mathrm{CH}_{3}\right]$ (ILVA) methyl labeling, ${ }^{72}$ the expression medium was prepared with ${ }^{15} \mathrm{~N}_{-} \mathrm{NH}_{4} \mathrm{Cl}_{2}(1 \mathrm{~g} / \mathrm{L}),{ }^{2} \mathrm{H}$-D-glucose $(3 \mathrm{~g} / \mathrm{L}), 99 \% \mathrm{D}_{2} \mathrm{O}$ and the following labeled substrates were added 1 hour prior to induction: $2-{ }^{2} \mathrm{H}, 3-{ }^{13} \mathrm{C}$-L-alanine $(0.7 \mathrm{~g} / \mathrm{L}),{ }^{2} \mathrm{H}$ succinate $(2.5 \mathrm{~g} / \mathrm{L}), 3,4,4,4-{ }^{2} \mathrm{H}, 3-{ }^{13} \mathrm{CH}_{3}$ - $\alpha$-ketoisovalerate $(0.12 \mathrm{~g} / \mathrm{L})$, and $3,3-{ }^{2} \mathrm{H}^{13} \mathrm{CH}_{3}-\alpha$-ketobuterate $(0.06 \mathrm{~g} / \mathrm{L})$. Cells were acclimated to the high $\mathrm{D}_{2} \mathrm{O}$ content in the expression media by a gradual increase in the $\mathrm{D}_{2} \mathrm{O} / \mathrm{H}_{2} \mathrm{O}$ ratio, as previously described. ${ }^{72}$ All isotopically labeled compounds were obtained from CIL. Cells were harvested by centrifugation at $4000 \mathrm{rpm}$ for $20 \mathrm{~min}$ at $4^{\circ} \mathrm{C}$ and pellets 
stored at $-20^{\circ} \mathrm{C}$ until needed. For purification, cell pellets were resuspended in $\sim 40 \mathrm{ml}$ (per $1 \mathrm{~L}$ growth) of HisBind A buffer (50mM Tris $\mathrm{pH} 7.5,500 \mathrm{mM} \mathrm{NaCl}, 10 \mathrm{mM}$ Imidazole, $10 \%$ Glycerol, $5 \mathrm{mM} \beta$ Mercaptoethanol (BME)) supplemented with 0.2mM PMSF, 1mM Benzamidine, 0.15mg/ml Lysozyme, and $1 \mathrm{mM}$ DTT, incubated on ice for $30 \mathrm{~min}$ and sonicated for 4-6 cycles of $60 \mathrm{sec}$ on ice followed by centrifugation at $23,000 \mathrm{~g}$ for $20 \mathrm{~min}$ at $4^{\circ} \mathrm{C}$. The protein was purified by a two-step $\mathrm{Ni}^{2+}$ affinity chromatography on an AKTA FPLC system (GE Amersham Pharmacia). Specifically, the lysate was loaded on a $2 \times 5 \mathrm{ml}$ HisTrap HP column (GE Healthcare) pre-equilibrated with HisBind A, washed for $\sim 10$ column volumes, and eluted with a linear gradient of buffer HisBind B (50mM Tris pH 7.5, 500mM $\mathrm{NaCl}, 500 \mathrm{mM}$ Imidazole, 10\% Glycerol, 5mM BME) over 7-10 column volumes. Protein fractions were combined and diluted with $50 \mathrm{mM}$ Tris $\mathrm{pH} 7.5,25 \mathrm{mM} \mathrm{NaCl}, 1 \mathrm{mM}$ DTT to a final $130-150 \mathrm{mM}$ $\mathrm{NaCl} / \sim 80 \mathrm{mM}$ Imidazole and the His tag was cleaved using an in-house (6X)His-tagged 3C protease ( $1.5 \mathrm{mg} / 1 \mathrm{~L}$ of growth) for 16 hours at $4^{\circ} \mathrm{C}$. The His tag, $3 \mathrm{C}$ protease enzyme and impurities were removed by re-passing the protein on a $5 \mathrm{ml}$ HisTrap HP column pre-equilibrated with HisBind A buffer supplemented with $30 \mathrm{mM}$ Imidazole and eluted in the wash step. Protein purity was assessed by $18 \%$ SDS-PAGE and pure fractions were concentrated, flash frozen, and stored at $-80^{\circ} \mathrm{C}$.

Xenopus Laevis histones $\mathrm{H} 2 \mathrm{~A}, \mathrm{H} 2 \mathrm{~B}, \mathrm{H} 3$, and $\mathrm{H} 4$ in pET3a plasmid were a gift from Prof. Gregory Bowman (Johns Hopkins University) and were expressed and purified as previously outlined $^{73-75}$ with some modifications. Briefly, histone plasmids were transformed in BL21(DE3) pLysS cells, grown in $2 x T Y$ medium with $100 \mathrm{mg} / \mathrm{L}$ carbenicillin at $37^{\circ} \mathrm{C}$ with shaking to a density of $\mathrm{OD}_{600} \sim$ 0.6 and induced with $0.3 \mathrm{mM}$ IPTG for 4 hours at $37^{\circ} \mathrm{C}$. Cells were harvested by centrifugation at $3000 \mathrm{rpm}$ for $20 \mathrm{~min}$ at $18^{\circ} \mathrm{C}$ and pellets stored at $-20^{\circ} \mathrm{C}$. Histones $\mathrm{H} 2 \mathrm{~A}, \mathrm{H} 2 \mathrm{~B}$ and $\mathrm{H} 3$ ( $2 \mathrm{~L}$ each) were purified using ion exchange chromatography under denaturing conditions according to a published method. ${ }^{75}$ Specifically, cell pellets were resuspended in buffer SAU 200 (40mM NaOAc pH 5.2, 7.8M Urea, $200 \mathrm{mM} \mathrm{NaCl}, 1 \mathrm{mM}$ EDTA pH 8.0, 10mM lysine, 5mM BME) supplemented with protease inhibitors (0.2mM PMSF, $1 \mathrm{mM}$ Benzamidine) and lysed by sonication for 6 cycles of $60 \mathrm{sec}$, then spun down at $23,000 \mathrm{~g}$ for $20 \mathrm{~min}$ at $4^{\circ} \mathrm{C}$. The lysate was loaded on a $20 \mathrm{ml}$ tandem Q-SP HiTrap HP column ( $2 \times 5 \mathrm{ml} \mathrm{Q}$ on top of $2 \times 5 \mathrm{ml} \mathrm{SP}$ ), washed for 10 column volumes, where the $\mathrm{Q}$ column was removed and the protein eluted from the SP column by a linear salt gradient over $10 \mathrm{col}$. vol. using buffer SAU 800 (40mM NaOAc pH 5.2, 7.8M Urea, 800mM NaCl, 1mM EDTA pH 8.0, 10mM lysine, 5mM BME). Protein fractions were analyzed by $18 \%$ SDS-PAGE, pooled and dialyzed 4 times against dd $\mathrm{H}_{2} \mathrm{O}$ with $5 \mathrm{mM}$ BME using a $3.5 \mathrm{kDa}$ cutoff membrane (Spectra Labs), then lyophilized and stored at $-20^{\circ} \mathrm{C}$. Histone H4 was prepared instead from inclusion bodies, followed by a desalting column (HiPrep 26/10 (GE)) and a tandem Q-SP column (GE), as previously described. ${ }^{73,74}$

\section{Nucleosome constructs and preparation}


The Sox2-Oct4 mFgf4 and mNanog composite sites were incorporated at different positions within the Widom 601 positioning sequence ${ }^{50}$ in pGEM-3z/601 plasmid (gift from Prof. Gregory Bowman, Johns Hopkins University), which was modified on one end to remove a strong non-cognate Sox2 binding site (see Table S1). Nucleosomal DNA was prepared by standard large-scale PCR (10-40ml) of the modified 601 sequences using in-house Taq DNA polymerase, 10X ThermoPol buffer (NEB), $0.5 \mathrm{mM}$ dNTPs (Invitrogen) and either unlabeled DNA primers (for NMR) or fluorescently 5'-end labeled (5'-(6FAM) on the top strand shown in Table S1, 5'-Cy3 on the bottom strand) primers obtained from IDT with HPLC purification (see Table S1). DNA was concentrated using an Amicon Ultra-15 centrifugal filter unit (10kDa cutoff, Millipore-Sigma) and purified by vertical gel electrophoresis on a 6\% $(60: 1$ Acrylamide/Bisacrylamide) native gel column using a 491 Prep Cell (Bio-rad) run at $10 \mathrm{~W}$ and $4^{\circ} \mathrm{C}$, as described. ${ }^{74}$ DNA fractions were analyzed on a $1.2 \%$ agarose gel, concentrated and stored at $-20^{\circ} \mathrm{C}$. DNA concentration was determined from absorbance at $260 \mathrm{~nm}$ measured on a NanoDrop device (Thermo Scientific) and using the extinction coefficient for duplex DNA (40ug/A 260$)$. Xenopus Laevis histone octamer was assembled by refolding each histone in $20 \mathrm{mM}$ Tris- $\mathrm{HCl} \mathrm{pH} 7.8,6 \mathrm{M}$ Guanidine$\mathrm{HCl}, 5 \mathrm{mM}$ DTT at $2 \mathrm{mg} / \mathrm{ml}$ and combining the four histone proteins with $20 \%$ molar excess of $\mathrm{H} 2 \mathrm{~A}$ and H2B (1:1:1.2:1.2), dialyzing 3-4 times against high salt buffer (10mM Tris- $\mathrm{HCl} \mathrm{pH} 7.8,2 \mathrm{M} \mathrm{NaCl}, 1 \mathrm{mM}$ EDTA, $5 \mathrm{mM}$ BME), followed by concentration to $\sim 1.4 \mathrm{ml}$ and gel filtration chromatography using a HiLoad 16/600 Superdex 200 pg column (GE), as per established protocols. ${ }^{73,74}$ The octamer and H2A-H2B dimer fractions were analyzed by 18-20\% SDS-PAGE, concentrated and flash frozen at $80^{\circ} \mathrm{C}$ for storage. Nucleosomes were reconstituted by combining purified histone octamer (6uM) with H2A-H2B dimer (1.8uM) and slight excess of DNA (6.6uM) in RBHigh buffer (10mM Tris pH 7.8, 2M $\mathrm{KCl}, 1 \mathrm{mM}$ EDTA, 1mM DTT), followed by salt gradient dialysis with RBLow buffer (10mM Tris $\mathrm{pH} 7.8$, $250 \mathrm{mM} \mathrm{KCl}, 1 \mathrm{mM}$ EDTA, $1 \mathrm{mM}$ DTT) over $\sim 24$ hours at $4^{\circ} \mathrm{C} .{ }^{73}, 74$ Nucleosomes were dialyzed overnight into elution buffer (10mM Tris $\mathrm{pH} 7.8,2.5 \mathrm{mM} \mathrm{KCl}, 1 \mathrm{mM}$ EDTA, $1 \mathrm{mM}$ DTT), concentrated, and purified by vertical gel electrophoresis on a $7 \%$ native gel column, as described for DNA above. ${ }^{74}$ Nucleosome fractions were analyzed using a $5 \%$ native gel and visualized by ethidium bromide staining or fluorescence imagining on a Typhoon 5 laser scanner (Amersham). Nucleosomes were concentrated, flash frozen $\left(10 \%\right.$ glycerol added), and stored at $-80^{\circ} \mathrm{C}$.

\section{Electrophoretic mobility shift assay (EMSA)}

For EMSA, 10nM of 5'-FAM/5'-Cy3-labeled nucleosome (NCP) or DNA were mixed with variable concentrations of Sox2 or Oct4 protein $(10 \mathrm{nM}$ to $1000 \mathrm{nM})$ in binding buffer $(10 \mathrm{mM}$ Tris- $\mathrm{HCl} \mathrm{pH} 7.5$, $150 \mathrm{mM} \mathrm{KCl}, 1 \mathrm{mM}$ EDTA pH 8.0, $1 \mathrm{mM}$ DTT, $0.5 \mathrm{mg} / \mathrm{ml}$ BSA, $5 \%$ glycerol) in a $20 \mu$ l total reaction volume and incubated at $25^{\circ} \mathrm{C}$ for $30 \mathrm{~min}$. Binding reactions $(2 \mu \mathrm{l})$ were loaded on a $5 \%$ native gel and run for $85 \mathrm{~min}$ (DNA) or $120 \mathrm{~min}(\mathrm{NCP})$ at $100 \mathrm{~V}$ at $4^{\circ} \mathrm{C}$. FAM and Cy3 fluorescence was measured on a Typhoon 9450 or 5 imager (GE Amersham) using excitation at $488 \mathrm{~nm}$ and $532 \mathrm{~nm}$, respectively, 
and the appropriate emission filters (standard protocol). The signal (volumes) corresponding to free and bound NCP (or DNA) species were quantified using ImageJ and the fraction bound ( $F_{\text {Bound }}$ ) was calculated from the ratio of bound to total NCP (or DNA). $F_{\text {Bound }}$ as a function of total protein concentration was fitted in Mathematica (Wolfram) to a 2-state binding model using the following quadratic equation to extract the apparent dissociation constant (see Table 1): $\mathrm{F}_{\text {bound }}(\mathrm{NCP})=\left(\left([\mathrm{N}]+\mathrm{K}_{d}\right.\right.$ $\left.+[P])-\left(\left([N]+K_{d}+[P]\right)^{2}-4[N][P]\right)^{1 / 2}\right) /(2[N])$, where $[N]$ is the total concentration of NCP or DNA $(10 n M),[P]$ is the total concentration of protein added (Sox2 or Oct4), and $K_{d}$ is the apparent dissociation constant. The $\mathrm{K}_{d}$ values and errors reported in Table 1 are the average and standard deviation of at least three technical replicates.

\section{Dnase I footprinting assay}

Binding reactions $(25 \mu \mathrm{l})$ of $100 \mathrm{nM}$ NCP or DNA with or without $1 \mu \mathrm{M}$ Sox2 and/or Oct4 were set up in $10 \mathrm{mM}$ Tris- $\mathrm{HCl} \mathrm{pH} 7.5,100 \mathrm{mM} \mathrm{KCl}, 1 \mathrm{mM}$ DTT, 0.2mg/ml BSA, 0.02\% Tween-20, 8\% Glycerol and incubated at $25^{\circ} \mathrm{C}$ for $30 \mathrm{~min}$. Next, $15 \mu \mathrm{l}$ of Dnasel solution, prepared from DNasel enzyme and $10 \mathrm{X}$ Dnasel reaction buffer (NEB), was added to $25 \mu \mathrm{l}$ of binding reactions so that the final conditions contained DNase I at $0.0125 \mathrm{U} / \mathrm{ul}$ for NCP and $0.0025 \mathrm{U} / \mathrm{ul}$ for DNA as well as $2.5 \mathrm{mM} \mathrm{MgCl}_{2}, 0.5 \mathrm{mM}$ $\mathrm{CaCl}_{2}$, and $100 \mathrm{mM} \mathrm{KCl}$. The reactions were incubated for $5 \mathrm{~min}$ at $25^{\circ} \mathrm{C}$ and stopped by adding $40 \mu \mathrm{l}$ of quench buffer (10mM Tris- $\mathrm{HCl} \mathrm{pH} 7.5,50 \mathrm{mM}$ EDTA, 2\% SDS, 300ng/ul Glycogen (Invitrogen)) and heating at $75^{\circ} \mathrm{C}$ for $30 \mathrm{~min}$. To purify DNA, reactions were mixed with an equal volume $(80 \mu \mathrm{l})$ of 25:24:1 phenol:chloroform:isoamyl alcohol (Sigma), briefly vortexed and centrifuged for 2 min at full speed (15,000 rpm). The aqueous (top) layer was placed in a clean tube and $80 \mu$ of $24: 1$ chloroform:isoamyl alcohol was added, vortexed and spun down as above. The top layer ( 80 $\mu$ l) was transferred to a clean tube again and DNA was ethanol precipitated overnight at $-20^{\circ} \mathrm{C}$ by mixing in 3 vol. of $100 \%$ Ethanol, 0.1 vol. of $3 \mathrm{M}$ Sodium Acetate, $\mathrm{pH} 5.2,0.04$ vol. of $1 \mathrm{M} \mathrm{MgCl}_{2}$, and $1 \mu \mathrm{l}$ of $5 \mathrm{mg} / \mathrm{ml}$ Salmon Sperm DNA (Invitrogen). The mixture was centrifuged at full speed (15,000 rpm) for 30 min at $4^{\circ} \mathrm{C}$ and pellets further washed twice with $80 \%$ ice cold ethanol by spinning at $4^{\circ} \mathrm{C}$ for $10 \mathrm{~min}$. The pellets were air dried for 30-60 min to remove any trace of ethanol and resuspended in $6 \mu$ l of formamide loading buffer (89mM Tris-borate $\mathrm{pH} 8.3,5 \mathrm{mM}$ EDTA, 95\% formamide (deionized), 0.2\% Orange $\mathrm{G}$ dye). The samples were directly run on an $8 \%$ denaturing sequencing gel $(8 \%(19: 1)$ Acrylamide/Bisacrylamide, $8 \mathrm{M}$ Urea, $1 \mathrm{X}$ TBE) at $65 \mathrm{~W}$ for 1.5 hours. Sequencing ladders were generated using the Thermo Sequenase Dye Primer Manual Cycle Sequencing Kit (Applied Biosystems). Gels were scanned within optically clear glass plates (VWR) and the FAM- or Cy3labeled DNA fragments were visualized separately on a Typhoon 5 laser scanner (Amersham) as described for EMSA. 


\section{Site-specific nucleosome crosslinking assay}

An NCP 54R $R_{F}$ construct was prepared harboring a single Cysteine (C) mutation in H2B (S53C) found in close proximity to the DNA backbone in the Sox2 binding motif. The H2B(S53C) histone octamer was a gift from Prof. Gregory Bowman (Johns Hopkins University) and has been shown to effectively crosslink with nucleosomal DNA in nucleosome sliding studies. ${ }^{56}$ APB labeling of nucleosomes was performed following published protocols with some modifications. ${ }^{55,76}$ Briefly, in the dark, the photolabile crosslinker 4-azidophenacyl bromide ${ }^{77}$ (APB, Abcam) was dissolved in 100\% DMF to $\sim 100 \mathrm{mM}$ and further diluted to $5 \mathrm{mM}$ in $10 \mathrm{mM}$ Tris- $\mathrm{HCl} \mathrm{pH} 7.5,10 \%$ Glycerol, 20\% DMF. APB at $250 \mu \mathrm{M}$ final was added to $1 \mu \mathrm{M}$ NCP $54 \mathrm{R}_{\mathrm{F}} \mathrm{H} 2 \mathrm{~B}(\mathrm{~S} 53 \mathrm{C})$, which had been buffer exchanged into a $10 \mathrm{mM}$ Tris- $\mathrm{HCl} \mathrm{pH} \mathrm{7.5,5 \%} \mathrm{glycerol} \mathrm{using} \mathrm{an} \mathrm{Amicon} \mathrm{Ultra-0.5} \mathrm{(10kDa} \mathrm{cutoff)} \mathrm{centrifugal} \mathrm{filter} \mathrm{unit} \mathrm{to} \mathrm{remove}$ DTT. The labeling reaction was incubated for 3 hours at $25^{\circ} \mathrm{C}$ and quenched by addition of $1 \mathrm{M}$ DTT to a final of $10 \mathrm{mM}$. Binding reactions of 100nM NCP with $1 \mu \mathrm{M}$ Sox2 and/or Oct4 were set up in binding buffer as for EMSA and incubated for $30 \mathrm{~min}$ at $25^{\circ} \mathrm{C}$. The reactions were irradiated with ultraviolet (UV) light for $1 \mathrm{~min}$ in the dark, mixed with $60 \mu \mathrm{l}$ of $20 \mathrm{mM}$ Tris $-\mathrm{HCl} \mathrm{pH} 8.0,0.2 \%$ SDS, $150 \mathrm{mM} \mathrm{NaCl}$, briefly vortexed, and heated at $70^{\circ} \mathrm{C}$ for $20 \mathrm{~min}$. An equal volume ( 80 $\left.\mathrm{ul}\right)$ of 5:1 phenol:chloroform (Sigma) was added to the mixture, briefly vortexed, and spun down for 2 min at 13,000rpm, where the crosslinked DNA ends up near the interface of the organic and aqueous phase. The samples were further processed and purified as previously described. ${ }^{76}$ Briefly, crosslinked DNA was washed (4 times with $1.0 \mathrm{M}$ Tris- $\mathrm{HCl} \mathrm{pH} 8.0,5 \% \mathrm{SDS}$ ) and purified by ethanol precipitation at $4^{\circ} \mathrm{C}$ overnight, cleaved selectively at the crosslinked site by base-catalyzed hydrolysis by adding $0.1 \mathrm{M} \mathrm{NaOH}$ for 40 min at $90^{\circ} \mathrm{C}$, neutralized with $\mathrm{HCl}$, and ethanol precipitated at $-20^{\circ} \mathrm{C}$ overnight. The dried DNA pellets were resuspended in $6 \mu$ l of formamide buffer and run on an $8 \%$ sequencing gel, scanned and processed as described above for DNasel footprinting.

\section{NMR spectroscopy}

NMR samples were prepared by exchanging the appropriate amounts of Sox2 protein or a mixture of Sox2 with unlabeled DNA, NCP 3 times into NMR buffer $(20 \mathrm{mM}$ Tris- $\mathrm{HCl}$ pH 7.0, $25 \mathrm{mM} \mathrm{NaCl}, 0.5$ mM TCEP, $1 \mathrm{mM}$ EDTA) using an Amicon Ultra-15 (10kDa cutoff) filter unit and centrifugation at $4000 \mathrm{rpm}$ and $4{ }^{\circ} \mathrm{C}$. Samples were adjusted to $\sim 300 \mu \mathrm{l}$ and $7.5 \% \mathrm{D}_{2} \mathrm{O}$, placed in a Shigemi tube, and stored at $4^{\circ} \mathrm{C}$ for 0-2 days before NMR data collection. All NMR experiments were carried out on a Bruker Avance $600 \mathrm{MHz}$ or Ascend $800 \mathrm{MHz}$ NMR spectrometer equipped with a triple-resonance cryoprobe. Backbone and sidechain assignments for the Sox2 HMG domain (WT and Y72A), free or bound to a short DNA duplex containing the mFgf4 site (sDNA ${ }_{F}, 5$ ' GACTCTTTGTTTGGC), were obtained from a standard suite of experiments (2D HSQC and 3D HNCO, HNCA, HNCACB, HNCOCACB, HCCH-TOCSY, and NOESY) acquired with non-uniform sampling (NUS) on a $0.4 \mathrm{mM}$ 
${ }^{13} \mathrm{C},{ }^{15} \mathrm{~N}$-labeled protein sample at $25^{\circ} \mathrm{C}$ ( 3 days collection time on $600 \mathrm{MHz}$ ). Backbone amide chemical shift perturbations (CSPs) for the Sox2 Y72A versus WT complex with sDNA $A_{F}$ were calculated from the difference in proton $\left(\delta_{\mathrm{H}}\right)$ and nitrogen $\left(\delta_{\mathrm{N}}\right)$ chemical shifts in ${ }^{1} \mathrm{H},{ }^{15} \mathrm{~N}-\mathrm{HSQC}$ spectra as follows: CSP $=\left(0.1 \Delta \delta_{\mathrm{N}}{ }^{2}+\Delta \delta_{\mathrm{H}}\right)^{1 / 2} \cdot{ }^{1} \mathrm{H}^{13} \mathrm{C}-\mathrm{HMQC}$ (methyl TROSY) correlation spectra were collected with 256 scans on $800 \mathrm{MHz} \mathrm{NMR}$ at $25^{\circ} \mathrm{C}(\sim 12$ hours) on $20 \mu \mathrm{M}$ samples of ILVA-methyl labeled Sox2 free or bound to unlabeled NCP $62_{\mathrm{F}}, 62_{\mathrm{N}}, 54 \mathrm{R}_{\mathrm{F}}, 27_{\mathrm{F}}$ or DNA $27_{\mathrm{F}}$ in 1:1.1 or 1:2.1 molar ratio. To make the ternary complex of ILVA-labeled Sox2 with NCP 62 and Oct4 at 1:2:1 and 1:2:2 ratios, unlabeled Oct4 DBD in NMR buffer was added to the Sox2-NCP (1:2) sample at 1 and 2 molar equivalents and the volume was adjusted down to $300 \mu \mathrm{l}$ by centrifugation at $10,000 \mathrm{rpm}$ and $4^{\circ} \mathrm{C}$ using an Amicon Ultra-0.5 (10kDa cutoff) filter unit. All NMR data was processed using nmrPipe ${ }^{78}$ and NESTA-NMR ${ }^{79}$ (NUS data), and analyzed using Sparky, ${ }^{80}$ Mathematica (Wolfram), and in-house scripts. Structural alignments and visualizations were performed using PyMOL (Schrödinger, LLC).

\section{Acknowledgements}

We thank Prof. Gregory Bowman at Johns Hopkins University for kindly providing materials and access to instrumentation, stimulating discussions, and critical review of the manuscript. We also thank Dr. Samaneh Kondalaji (Washington University at Saint Louis) for providing critical comments on the manuscript. We are very thankful to members of the Bowman lab, particularly Dr. Ilana Nodelman, for help with various experimental procedures and many beneficial discussions. We are grateful to Dr. Ananya Majumdar, director of the Biomolecular NMR center at Johns Hopkins University, for assistance with NMR data collection and processing. This work was supported by startup funds provided to E.N.N. by Johns Hopkins University. 


\section{Figures and Tables}

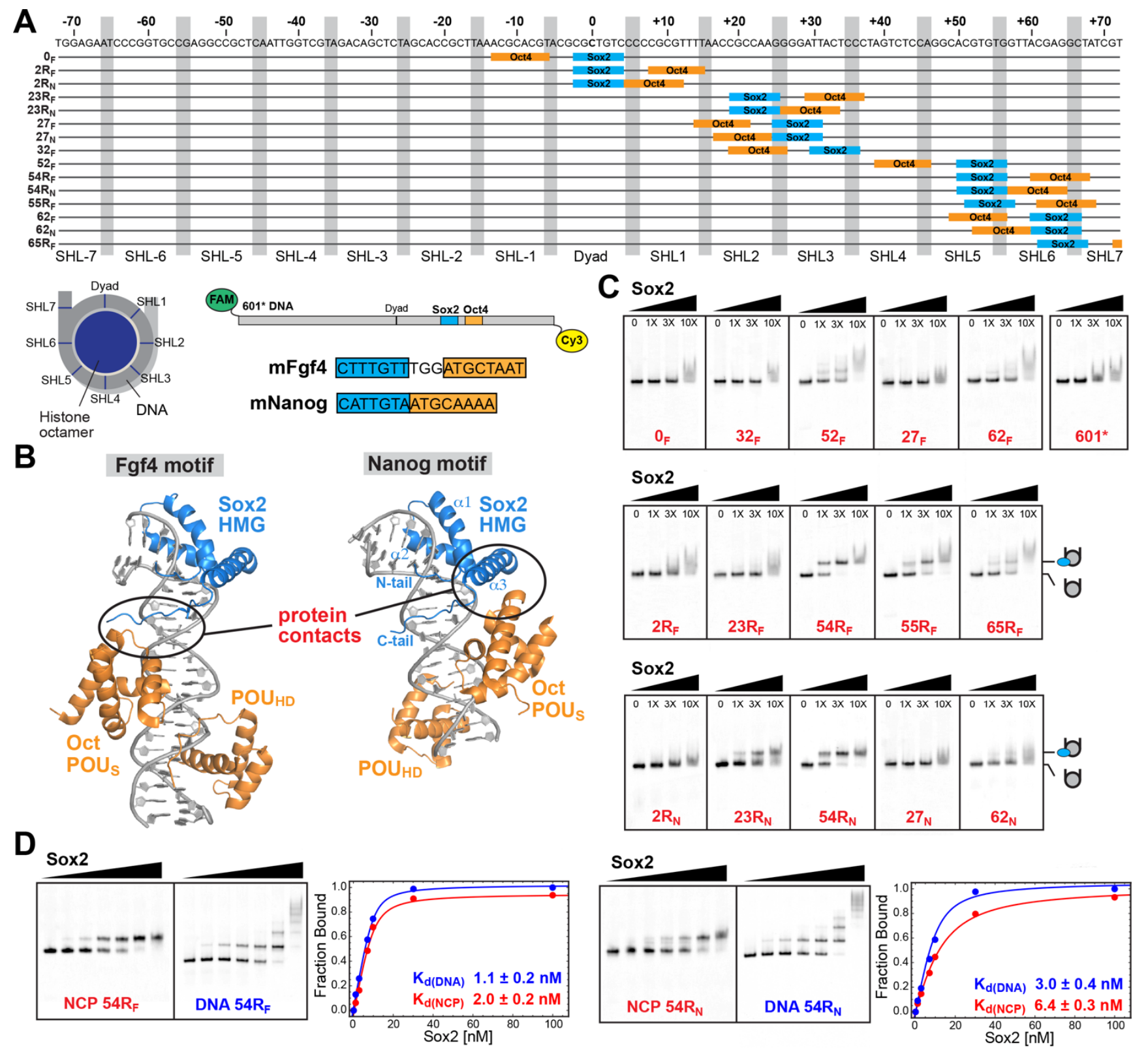

Figure 1. Sox2 binding to nucleosomes favors SHL5 but is highly position and DNA sequence dependent. (A) DNA constructs containing the Sox2-Oct4 composite motif (mFgf4 or mNanog) at different translational and rotational positions on the nucleosome. The motifs were inserted in a 145 base-pair modified Widom 601 sequence (601*, shown on top) that was double-labeled with a 5'-FAM (strand shown) and 5'-Cy3 fluorescence probes for biochemical assays. The nucleotides are numbered from -72 to +72 around the dyad (0) and each superhelical location (SHL) is indicated below the sequence and on the NCP cartoon. The grey rectangles highlight the narrow minor groove facing towards the histone core, including the strong positioning TpA dinucleotide steps. (B) Models of Sox2 and Oct4 binding to mFgf4 and mNanog composite motifs based on crystal (left, PDB ID: 1GT0) 
and NMR (right, PDB ID: 1O4X) structures of Sox2-Oct1-DNA (Oct1 is a close homolog of Oct4). (C) EMSA data for the Sox2 HMG domain binding (0-100nM) to different NCP constructs (10nM) showing variations with position and binding motif sequence. The highest affinity complex is formed with NCP 54R for both mFgf4 and mNanog motifs. (C) Representative EMSA titrations of Sox2 HMG (0-100nM) with NCP or DNA 54R constructs $(10 \mathrm{nM})$ and corresponding best fits to a two-state binding model with apparent dissociation constants $\left(\mathrm{K}_{\mathrm{d}}\right.$, inset). $\mathrm{K}_{\mathrm{d}}$ values and errors were calculated as the average and standard deviation of at least three independent measurements. 
Table 1. Apparent binding affinities $\left(\mathrm{K}_{\mathrm{d}}\right)$ of Sox2 or Oct4 for different DNA and NCP constructs containing the mFgf4 or mNanog site.

\begin{tabular}{|c|c|c|}
\hline & \multicolumn{2}{|c|}{$K_{d}(n M)$} \\
\hline Construct & Sox2 & Oct4 \\
\hline \multicolumn{3}{|l|}{$m F g f 4$} \\
\hline DNA 2 $R_{F}$ & $3.3 \pm 0.5$ & \\
\hline DNA $54 \mathrm{R}_{\mathrm{F}}$ & $1.1 \pm 0.2$ & $32 \pm 3$ \\
\hline DNA $62_{F}$ & $2.1 \pm 0.2$ & \\
\hline $\mathrm{NCP} 2 \mathrm{R}_{\mathrm{F}}$ & $31 \pm 4$ & \\
\hline $\mathrm{NCP} 23 \mathrm{R}_{\mathrm{F}}$ & $37 \pm 4$ & \\
\hline $\mathrm{NCP} 54 \mathrm{R}_{\mathrm{F}}$ & $2.0 \pm 0.2$ & $240 \pm 30$ \\
\hline $\mathrm{NCP} 55 \mathrm{R}_{\mathrm{F}}$ & $8.3 \pm 1.0$ & $110 \pm 10$ \\
\hline $\mathrm{NCP} 65 \mathrm{R}_{\mathrm{F}}$ & $12.4 \pm 1.2$ & \\
\hline $\mathrm{NCP} 0_{F}$ & $29 \pm 3$ & \\
\hline NCP $27_{F}$ & $34 \pm 4$ & \\
\hline NCP $32_{F}$ & $24 \pm 3$ & \\
\hline NCP $52_{F}$ & $11.1 \pm 1.4$ & \\
\hline NCP $62_{F}$ & $41 \pm 7$ & $390 \pm 50$ \\
\hline \multicolumn{3}{|l|}{ mNanog } \\
\hline DNA $2 R_{N}$ & $3.7 \pm 0.5$ & \\
\hline DNA $54 R_{N}$ & $3.0 \pm 0.4$ & $38 \pm 4$ \\
\hline DNA $62_{N}$ & $2.3 \pm 0.3$ & \\
\hline $\mathrm{NCP} 2 \mathrm{R}_{\mathrm{N}}$ & $23 \pm 3$ & \\
\hline $\mathrm{NCP} 23 \mathrm{R}_{\mathrm{N}}$ & $12.7 \pm 1.3$ & \\
\hline $\mathrm{NCP} 54 \mathrm{R}_{\mathrm{N}}$ & $6.4 \pm 0.3$ & $250 \pm 20$ \\
\hline $\mathrm{NCP} 27_{N}$ & $33 \pm 4$ & \\
\hline $\mathrm{NCP} 62_{\mathrm{N}}$ & $38 \pm 5$ & $110 \pm 10$ \\
\hline \multicolumn{3}{|l|}{ No motif } \\
\hline DNA $601^{*}$ & $8.0 \pm 0.7$ & $160 \pm 20$ \\
\hline NCP $601^{*}$ & $41 \pm 4$ & $350 \pm 40$ \\
\hline
\end{tabular}




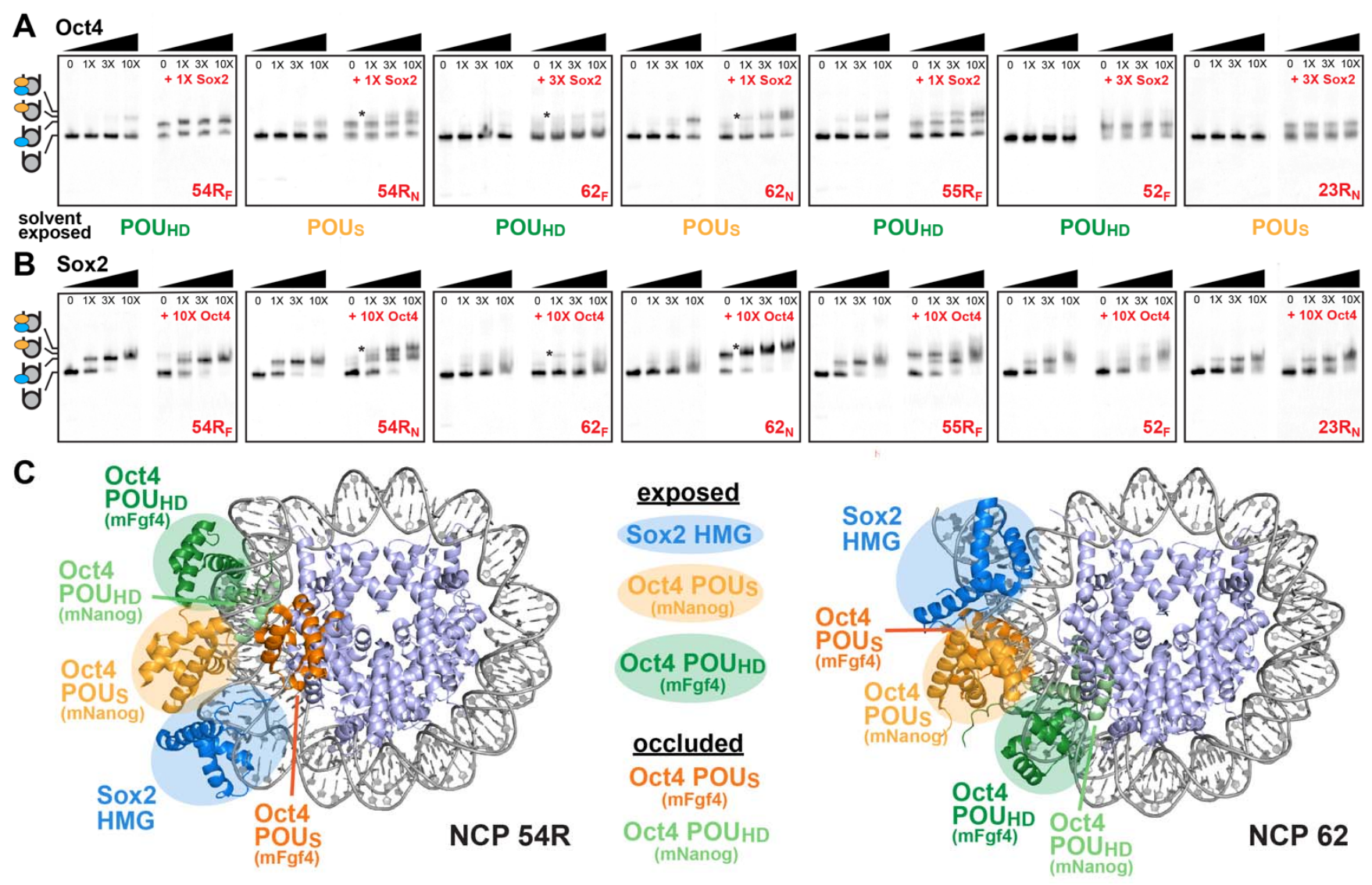

Figure 2. Nucleosome position and spacing of the composite motif affect Oct4 binding and Sox2-Oct4 synergism. (A) EMSA of Oct4 (0-100nM) binding alone or in the presence of Sox2 (10 or 30nM) to NCP constructs (10nM). The Oct4 subunit, $\mathrm{POU}_{S}$ or $P O U_{H D}$, whose half-site is solvent exposed in each NCP construct is highlighted below each gel. (B) EMSA of Sox2 (0-100nM) binding alone or in the presence of Oct4 (100nM) to NCP constructs (10nM). The tertiary Sox2-Oct4-NCP complex is observed to variable extent for certain composite motifs near SHL5 and 6, denoted by an asterix $\left(^{*}\right)$, and not observed for more internal sites. (C) Overlay of the cryo-EM structures of Sox2-Oct4 bound to a nucleosome at the same positions as in NCP 54R (PDB ID: 6YOV) and in NCP 62 (PDB ID: 6T90) with the NMR or crystal structure of the Sox2-Oct1-DNA complex on a canonical (PDB ID: 1O4X) or the mFgf4 (PDB ID: 1GT0) composite motif. For mNanog (canonical) motifs, Sox2 HMG (blue) and Oct4 $\mathrm{POU}_{\mathrm{S}}$ (light orange) are predicted to bind the outer-facing DNA surface and can synergize, while Oct4 $\mathrm{POU}_{\mathrm{HD}}$ (light green) is predicted to bind the occluded DNA surface and likely adopts an

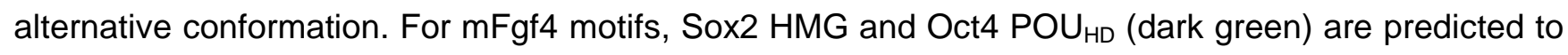
bind the exposed DNA surface and Oct4 POU (dark orange) is predicted to overlap with the histone core (NCP 54R) or other DNA gyre (NCP 62). There, cooperative binding would require partial DNA dissociation. 
A

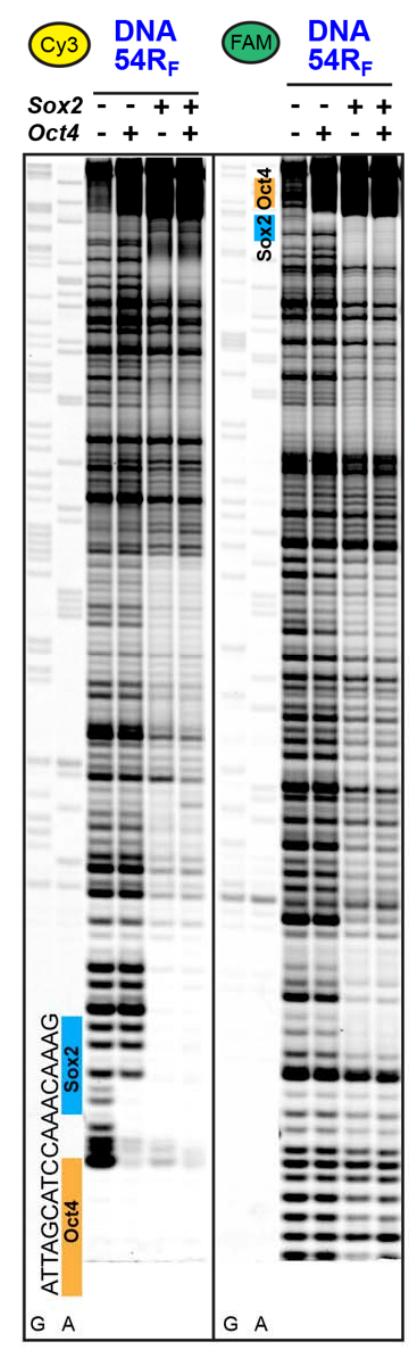

Pinpointing Sox2 and Oct4 binding by DNasel footprinting
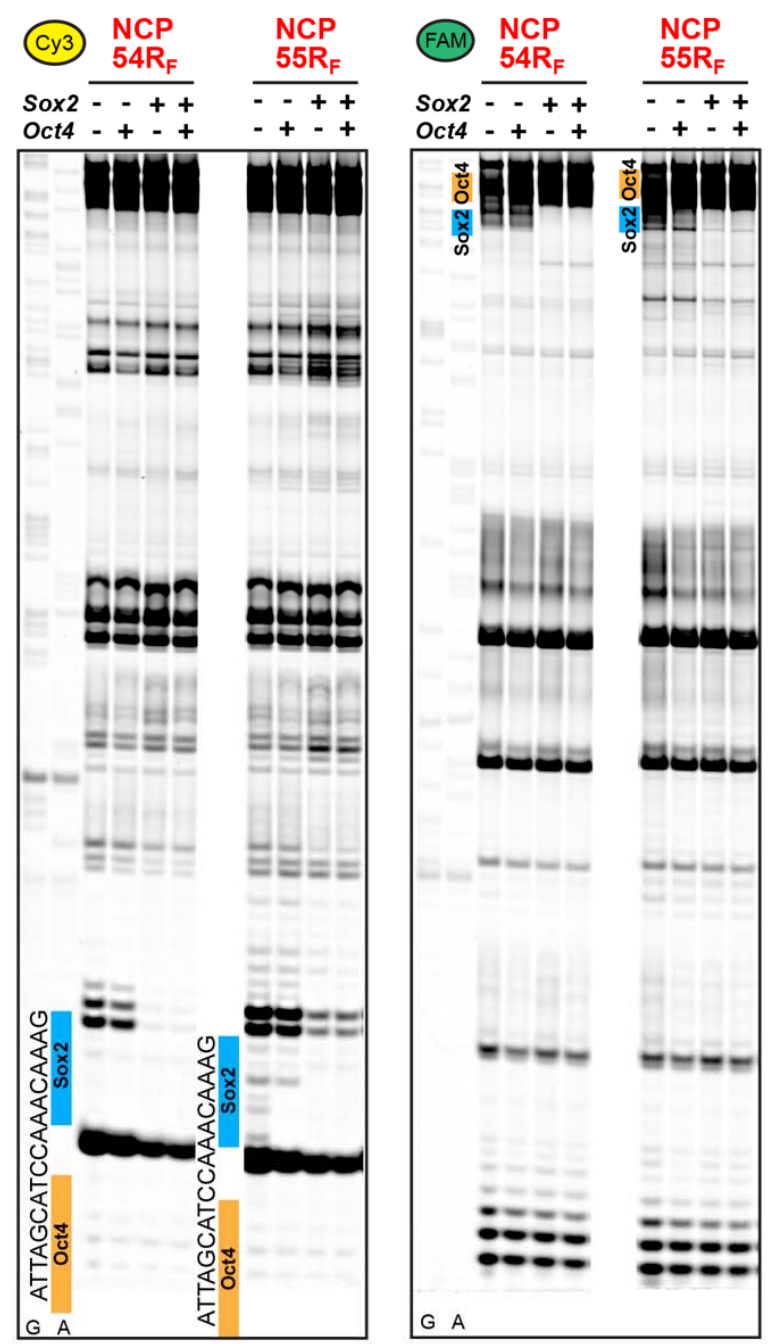

B APB crosslinking

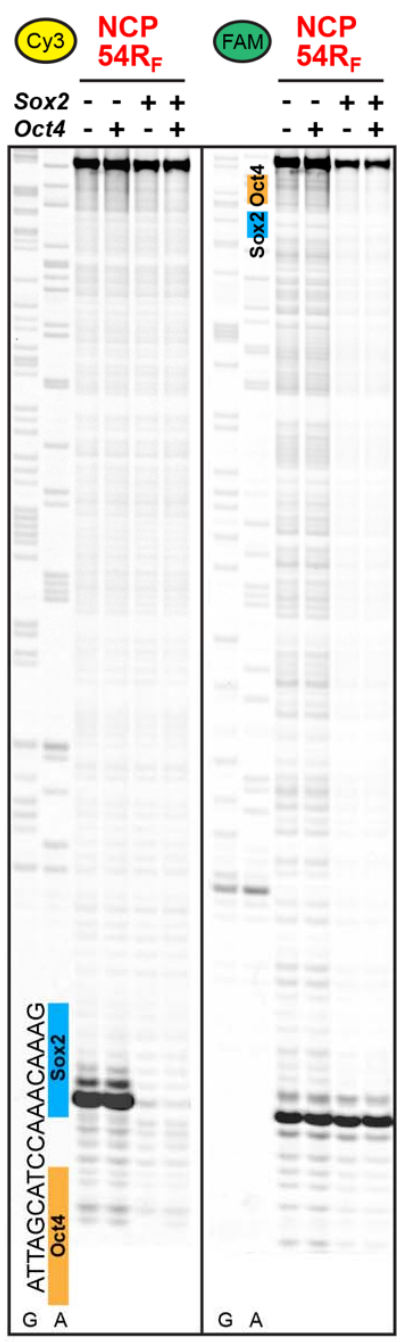

Figure 3. The high-affinity Sox2-nucleosome complex at SHL5 features a large DNA deformation. (A) DNasel footprinting assay of Sox2 and Oct4 $\left(1 \mu \mathrm{M}\right.$ each) binding to DNA $54 R_{F}(100 n M)$ or NCP $54 R_{F}$ and $55 R_{F}(100 n M)$. The position and sequence of the Sox2 (blue) and Oct4 (orange) site on the mFgf4 composite motif is indicated on each gel. A clear footprint for Sox2 and Oct4 near their motifs on free DNA indicates site-specific binding (Sox2 shows non-specific binding at other sites). A clear footprint for Sox2 near its motif in NCP shows stable complex formation at SHL5. The Oct4 footprint on NCP is not clearly observed due to proximity to DNA ends and/or faster kinetics. (B) APB crosslinking assay of

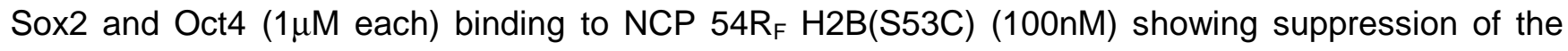
histone-DNA crosslink in the presence of Sox2 (but not Oct4). This is consistent with a large proteininduced DNA deformation. (DNA ladders for $G$ and $A$ nucleotides may vary slightly in sequence from constructs shown in gels.) 
bioRxiv preprint doi: https://doi.org/10.1101/2022.01.18.476780; this version posted January 21, 2022. The copyright holder for this preprint (which was not certified by peer review) is the author/funder. All rights reserved. No reuse allowed without permission.

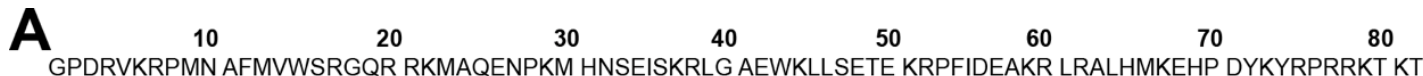
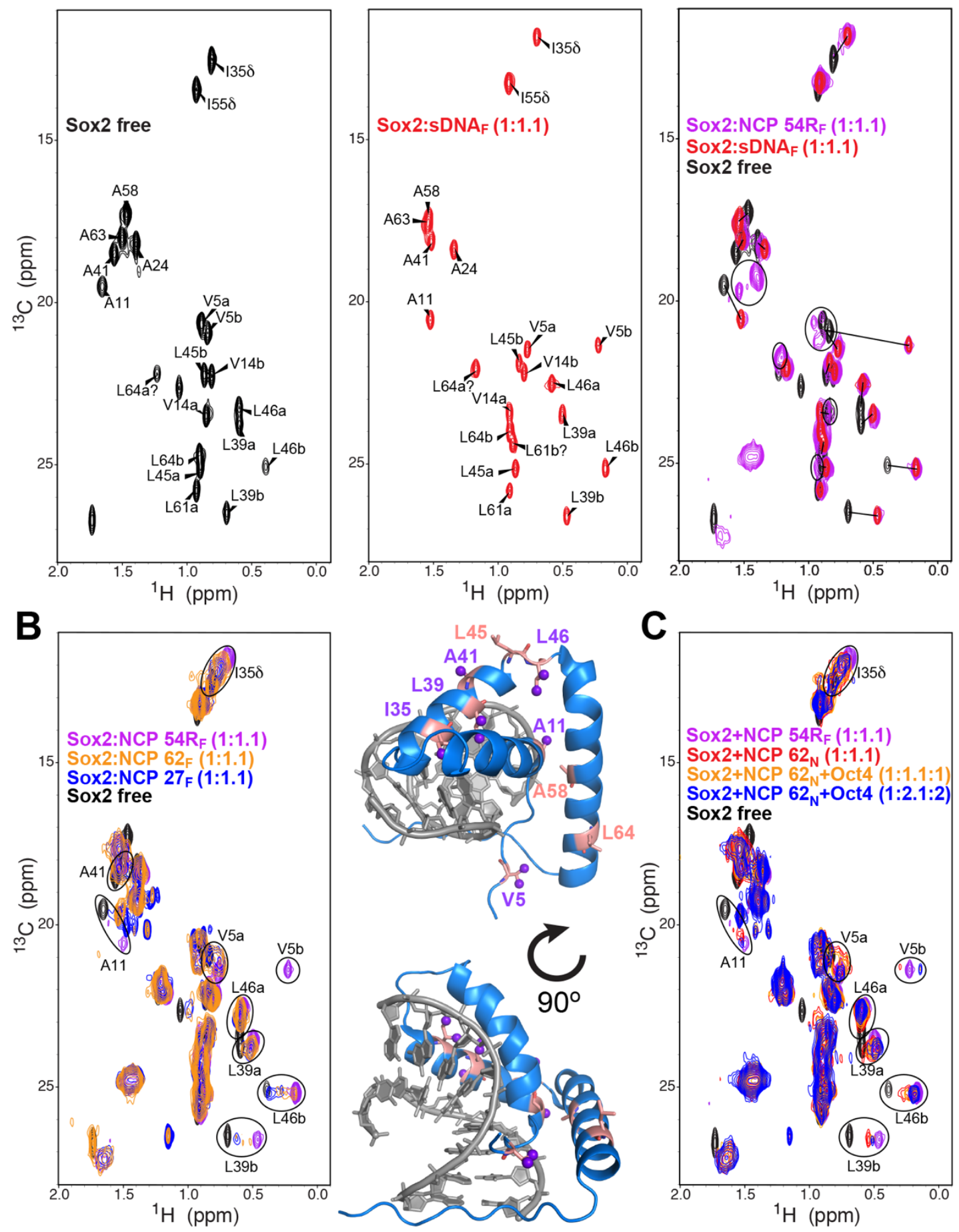

Figure 4. The conformation of Sox2 bound at SHL5 mimics the stable DNA-bound state but is dynamic at suboptimal nucleosome positions. (A) ${ }^{1} \mathrm{H},{ }^{13} \mathrm{C}-\mathrm{HMQC}$ methyl NMR spectra of ILVA-labeled Sox2 HMG domain (residues 3-82) in the free state (black) and bound to a short DNA (red, sDNA F $_{\text {) or }}$ NCP 54R $\mathrm{R}_{\mathrm{F}}$ (violet) containing the mFgf4 motif. Assignments for the Sox2 free and DNA-bound state are indicated. The spectral overlay (right) shows similar chemical shifts between the DNA- and NCP- 
bound states of Sox2 and large chemical shift changes relative to the Sox2 free state. Some peaks in the Sox2-NCP 54RF complex (circled) match peaks for the Sox2 free state and could reflect incomplete saturation or alternative conformations. (B) Overlay of ${ }^{1} \mathrm{H},{ }^{13} \mathrm{C}-\mathrm{HMQC}$ spectra of the ILVAlabeled Sox2 bound to nucleosomes with different binding affinities (left) showing that certain residues (circled) in NCP 27F and 62 F complexes occupy chemical shifts between the Sox2 free and DNAbound state. Structure of Sox2 bound to DNA (PDB ID: 1GT0) highlighting residues that undergo large chemical shift changes between the free and DNA-bound state (salmon) shown in (A). Methyl groups that exhibit chemical shift changes between different NCP complexes in spectra on the left (circled) are displayed as purple spheres and coincide with residues in salmon. (C) Overlay of ${ }^{1} \mathrm{H},{ }^{13} \mathrm{C}$-HMQC spectra of the ILVA-labeled Sox2 bound to NCP $62_{N}$ in the presence and absence of Oct4. The tertiary Sox2-Oct4-NCP complex near SHL6 shows persistent line broadening and chemical shift differences relative to the high-affinity Sox2-NCP $54 R_{F}$ complex (violet) with excess Oct4 and NCP. 
A

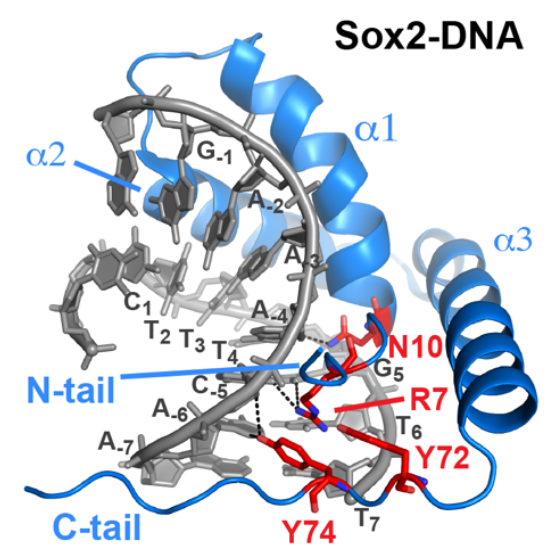

B

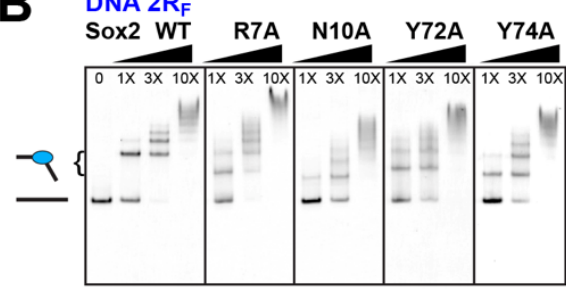

\section{DNA $2 R_{N}$}
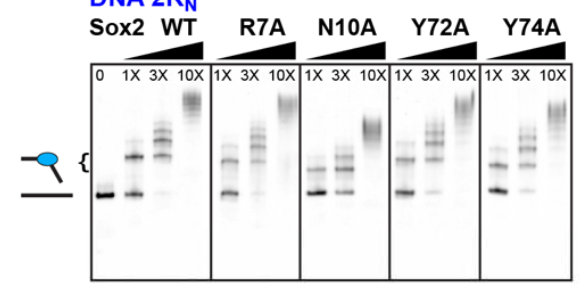
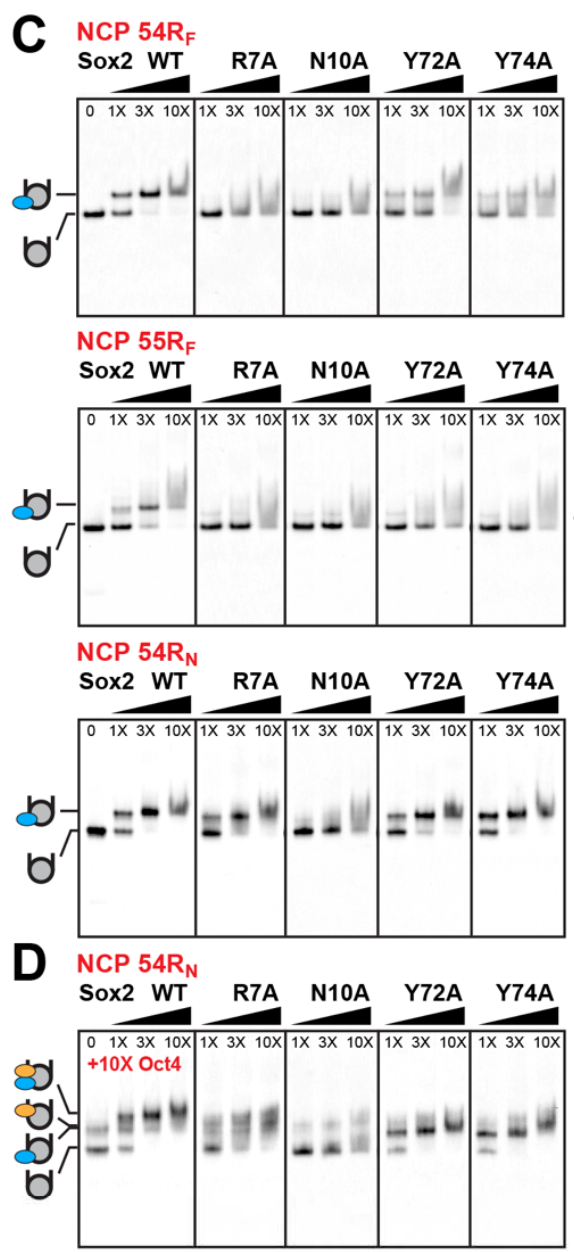

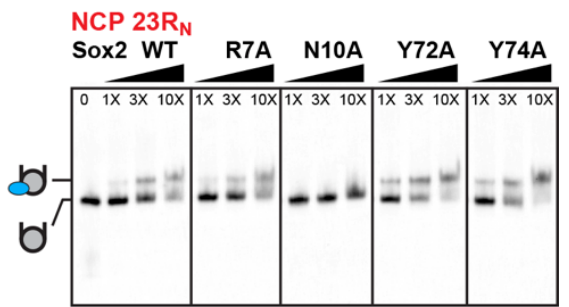

NCP $62_{F}$

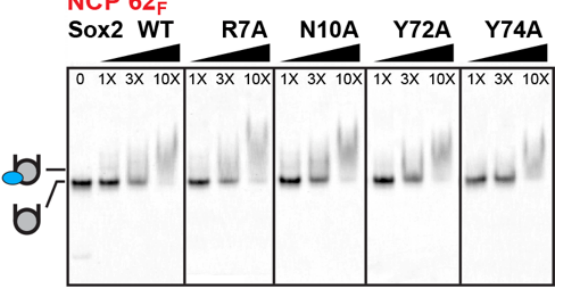

NCP $62_{\mathrm{N}}$

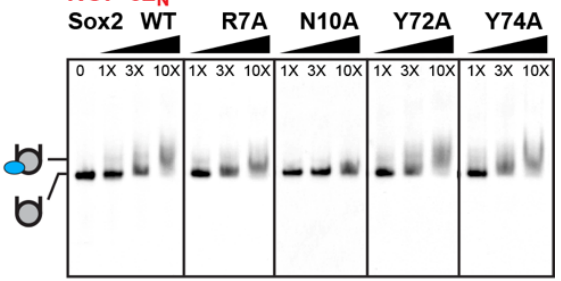

NCP $62_{\mathrm{N}}$

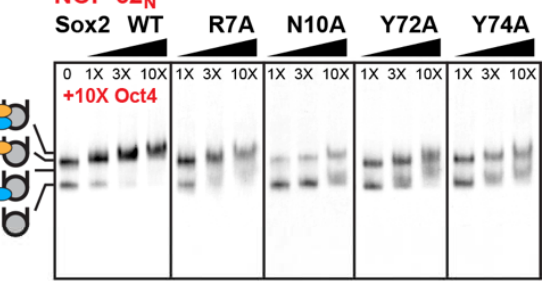

$\mathbf{E}$
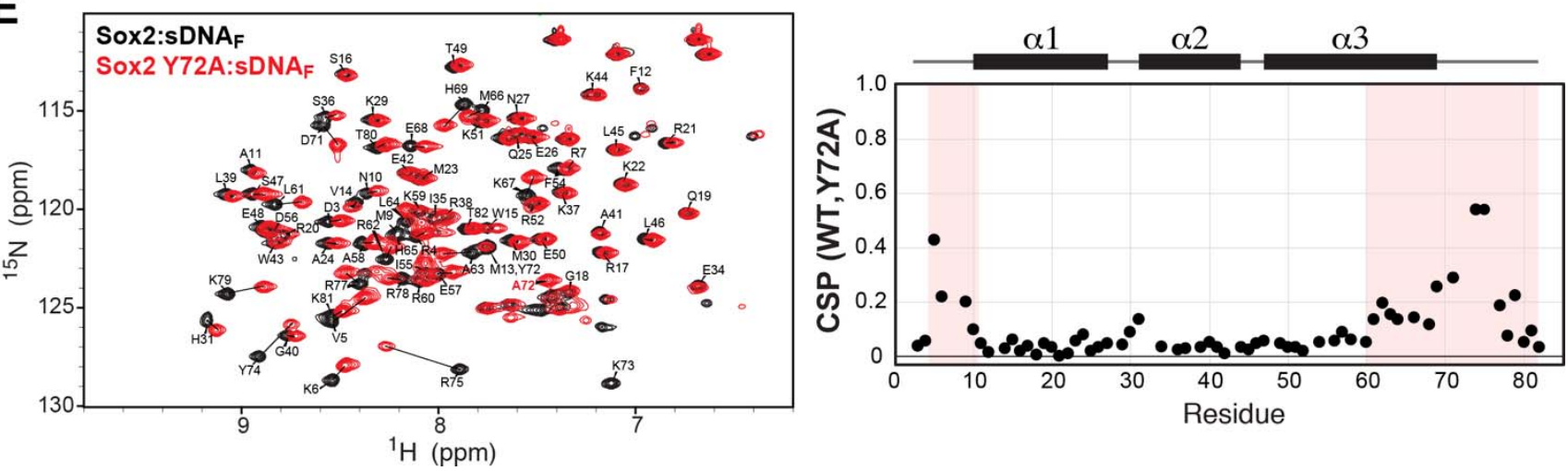

Figure 5. Impaired Sox2 folding and DNA bending activity differentially inhibit nucleosome binding and Sox2-Oct4 synergism. (A) Structure of Sox2 HMG domain (blue) bound to DNA (grey) containing the mFgf4 motif (numbered) (PDB ID: 1GT0). Highlighted in red are residues in the $\mathrm{N}$-terminal tail (N-tail, R7), C-terminal tail (C-tail, Y72A and Y74A) or internal ( $\alpha 1$-helix, N10) positions mutated in this study. (B) EMSA of Sox2 WT and mutants $(0-100 \mathrm{nM})$ binding to DNA (10nM) containing the mFgf4 $\left(2 \mathrm{R}_{\mathrm{F}}\right)$ or Nanog $\left(2 R_{N}\right)$ motif. The variable gel migration for the specific Sox2-DNA complex with different motif sequences or Sox2 mutations indicates variations in DNA bending (slower migration correlates with larger bending). (C) EMSA of Sox2 WT and mutants $(0-100 \mathrm{nM})$ binding to various NCP constructs (10 
$\mathrm{nM}$ ) showing overall larger effects of Sox2 mutations on the mFgf4 than mNanog motifs. (D) EMSA of Sox2 WT and mutants $(0-100 n M)$ binding to NCP $54 R_{N}$ and $62_{N}(10 n M)$ in the presence of Oct4 (100nM) showing that Sox2 mutants significantly impair the tertiary complex. (E) Overlay of ${ }^{1} \mathrm{H},{ }^{15} \mathrm{~N}$ HSQC spectra of backbone amides for Sox2 WT (black) and Y72A (red) bound to a short DNA duplex (sDNA $A_{F}$ ) containing the mFgf4 motif. Chemical shift perturbations (CSPs) for Sox2 WT versus Y72A are plotted on the right as a function of residue number. Large CSPs (highlighted) and chemical exchange broadening are detected around the mutation site in the C-terminal tail and $\alpha 3$-helix, the $\mathrm{N}$ terminal tail, and some internal residues, indicating changes in the conformation and dynamics of Sox2. Certain overlapped and severely broadened peaks as well as the mutated residue were omitted. 


\section{References}

1. Luger, K.; Mader, A. W.; Richmond, R. K.; Sargent, D. F.; Richmond, T. J., Crystal structure of the nucleosome core particle at 2.8 A resolution. Nature 1997, 389 (6648), 251-60.

2. McGinty, R. K.; Tan, S., Nucleosome structure and function. Chem Rev 2015, 115 (6), 2255-73.

3. Klemm, S. L.; Shipony, Z.; Greenleaf, W. J., Chromatin accessibility and the regulatory epigenome. Nat Rev Genet 2019, 20 (4), 207-220.

4. Cramer, P., Organization and regulation of gene transcription. Nature 2019, 573 (7772), 45-54.

5. Todeschini, A. L.; Georges, A.; Veitia, R. A., Transcription factors: specific DNA binding and specific gene regulation. Trends Genet 2014, 30 (6), 211-9.

6. Mao, C.; Brown, C. R.; Griesenbeck, J.; Boeger, H., Occlusion of regulatory sequences by promoter nucleosomes in vivo. PLoS One 2011, 6 (3), e17521.

7. Lorch, Y.; LaPointe, J. W.; Kornberg, R. D., Nucleosomes inhibit the initiation of transcription but allow chain elongation with the displacement of histones. Cell 1987, 49 (2), 203-10.

8. Ho, L.; Crabtree, G. R., Chromatin remodelling during development. Nature 2010, 463 (7280), 474-84.

9. Zaret, K. S.; Carroll, J. S., Pioneer transcription factors: establishing competence for gene expression. Genes Dev 2011, 25 (21), 2227-41.

10. Zaret, K. S.; Mango, S. E., Pioneer transcription factors, chromatin dynamics, and cell fate control. Curr Opin Genet Dev 2016, 37, 76-81.

11. Cirillo, L. A.; McPherson, C. E.; Bossard, P.; Stevens, K.; Cherian, S.; Shim, E. Y.; Clark, K. L.; Burley, S. K.; Zaret, K. S., Binding of the winged-helix transcription factor HNF3 to a linker histone site on the nucleosome. EMBO J 1998, $17(1), 244-54$.

12. Zaret, K. S., Pioneer Transcription Factors Initiating Gene Network Changes. Annu Rev Genet 2020, 54, 367-385.

13. Iwafuchi-Doi, M.; Zaret, K. S., Pioneer transcription factors in cell reprogramming. Genes Dev 2014, 28 (24), 2679-92.

14. Mayran, A.; Khetchoumian, K.; Hariri, F.; Pastinen, T.; Gauthier, Y.; Balsalobre, A.; Drouin, J., Pioneer factor Pax7 deploys a stable enhancer repertoire for specification of cell fate. Nat Genet 2018, 50 (2), 259-269.

15. Li, R.; Cauchy, P.; Ramamoorthy, S.; Boller, S.; Chavez, L.; Grosschedl, R., Dynamic EBF1 occupancy directs sequential epigenetic and transcriptional events in B-cell programming. Genes Dev 2018, 32 (2), 96-111.

16. Fuglerud, B. M.; Ledsaak, M.; Rogne, M.; Eskeland, R.; Gabrielsen, O. S., The pioneer factor activity of c-Myb involves recruitment of p300 and induction of histone acetylation followed by acetylation-induced chromatin dissociation. Epigenetics Chromatin 2018, 11 (1), 35.

17. Michael, A. K.; Grand, R. S.; Isbel, L.; Cavadini, S.; Kozicka, Z.; Kempf, G.; Bunker, R. D.; Schenk, A. D.; Graff-Meyer, A.; Pathare, G. R.; Weiss, J.; Matsumoto, S.; Burger, L.; Schubeler, D.; Thoma, N. H., Mechanisms of OCT4-SOX2 motif readout on nucleosomes. Science 2020, 368 (6498), 1460-1465.

18. Dodonova, S. O.; Zhu, F.; Dienemann, C.; Taipale, J.; Cramer, P., Nucleosome-bound SOX2 and SOX11 structures elucidate pioneer factor function. Nature 2020, 580 (7805), 669-672.

19. Makowski, M. M.; Gaullier, G.; Luger, K., Picking a nucleosome lock: Sequence- and structurespecific recognition of the nucleosome. J Biosci 2020, 45.

20. Smale, S. T., Pioneer factors in embryonic stem cells and differentiation. Curr Opin Genet Dev 2010, 20 (5), 519-26.

21. Lai, X.; Verhage, L.; Hugouvieux, V.; Zubieta, C., Pioneer Factors in Animals and PlantsColonizing Chromatin for Gene Regulation. Molecules 2018, 23 (8).

22. Iwafuchi-Doi, M.; Zaret, K. S., Cell fate control by pioneer transcription factors. Development 2016, 143 (11), $1833-7$.

23. Fernandez Garcia, M.; Moore, C. D.; Schulz, K. N.; Alberto, O.; Donague, G.; Harrison, M. M.; Zhu, H.; Zaret, K. S., Structural Features of Transcription Factors Associating with Nucleosome Binding. Mol Cell 2019, 75 (5), 921-932 e6. 
24. Weina, K.; Utikal, J., SOX2 and cancer: current research and its implications in the clinic. Clin Transl Med 2014, 3, 19.

25. Wuebben, E. L.; Rizzino, A., The dark side of SOX2: cancer - a comprehensive overview. Oncotarget 2017, 8 (27), 44917-44943.

26. Villodre, E. S.; Kipper, F. C.; Pereira, M. B.; Lenz, G., Roles of OCT4 in tumorigenesis, cancer therapy resistance and prognosis. Cancer Treat Rev 2016, 51, 1-9.

27. Jozwik, K. M.; Carroll, J. S., Pioneer factors in hormone-dependent cancers. Nat Rev Cancer 2012, $12(6), 381-5$.

28. Zhu, F.; Farnung, L.; Kaasinen, E.; Sahu, B.; Yin, Y.; Wei, B.; Dodonova, S. O.; Nitta, K. R.; Morgunova, E.; Taipale, M.; Cramer, P.; Taipale, J., The interaction landscape between transcription factors and the nucleosome. Nature 2018, 562 (7725), 76-81.

29. Yan, C.; Chen, H.; Bai, L., Systematic Study of Nucleosome-Displacing Factors in Budding Yeast. Mol Cell 2018, 71 (2), 294-305 e4.

30. Clark, K. L.; Halay, E. D.; Lai, E.; Burley, S. K., Co-crystal structure of the HNF-3/fork head DNArecognition motif resembles histone H5. Nature 1993, 364 (6436), 412-20.

31. Iwafuchi-Doi, M.; Donahue, G.; Kakumanu, A.; Watts, J. A.; Mahony, S.; Pugh, B. F.; Lee, D.; Kaestner, K. H.; Zaret, K. S., The Pioneer Transcription Factor FoxA Maintains an Accessible Nucleosome Configuration at Enhancers for Tissue-Specific Gene Activation. Mol Cell 2016, 62 (1), 79-91.

32. Hou, L.; Srivastava, Y.; Jauch, R., Molecular basis for the genome engagement by Sox proteins. Semin Cell Dev Biol 2017, 63, 2-12.

33. Soufi, A.; Garcia, M. F.; Jaroszewicz, A.; Osman, N.; Pellegrini, M.; Zaret, K. S., Pioneer transcription factors target partial DNA motifs on nucleosomes to initiate reprogramming. Cell 2015, 161 (3), 555-568.

34. Liu, Z.; Kraus, W. L., Catalytic-Independent Functions of PARP-1 Determine Sox2 Pioneer Activity at Intractable Genomic Loci. Mol Cell 2017, 65 (4), 589-603 e9.

35. Kashyap, V.; Rezende, N. C.; Scotland, K. B.; Shaffer, S. M.; Persson, J. L.; Gudas, L. J.; Mongan, N. P., Regulation of stem cell pluripotency and differentiation involves a mutual regulatory circuit of the NANOG, OCT4, and SOX2 pluripotency transcription factors with polycomb repressive complexes and stem cell microRNAs. Stem Cells Dev 2009, 18 (7), 1093-108.

36. Soufi, A.; Donahue, G.; Zaret, K. S., Facilitators and impediments of the pluripotency reprogramming factors' initial engagement with the genome. Cell 2012, 151 (5), 994-1004.

37. Voong, L. N.; Xi, L.; Sebeson, A. C.; Xiong, B.; Wang, J. P.; Wang, X., Insights into Nucleosome Organization in Mouse Embryonic Stem Cells through Chemical Mapping. Cell 2016, 167 (6), 1555-1570 e15.

38. Ng, C. K.; Li, N. X.; Chee, S.; Prabhakar, S.; Kolatkar, P. R.; Jauch, R., Deciphering the SoxOct partner code by quantitative cooperativity measurements. Nucleic Acids Res 2012, 40 (11), 493341.

39. Rodda, D. J.; Chew, J. L.; Lim, L. H.; Loh, Y. H.; Wang, B.; Ng, H. H.; Robson, P., Transcriptional regulation of nanog by OCT4 and SOX2. J Biol Chem 2005, 280 (26), 24731-7.

40. Wang, J.; Rao, S.; Chu, J.; Shen, X.; Levasseur, D. N.; Theunissen, T. W.; Orkin, S. H., A protein interaction network for pluripotency of embryonic stem cells. Nature 2006, 444 (7117), 364-8.

41. Chen, X.; Xu, H.; Yuan, P.; Fang, F.; Huss, M.; Vega, V. B.; Wong, E.; Orlov, Y. L.; Zhang, W.; Jiang, J.; Loh, Y. H.; Yeo, H. C.; Yeo, Z. X.; Narang, V.; Govindarajan, K. R.; Leong, B.; Shahab, A.; Ruan, Y.; Bourque, G.; Sung, W. K.; Clarke, N. D.; Wei, C. L.; Ng, H. H., Integration of external signaling pathways with the core transcriptional network in embryonic stem cells. Cell 2008, 133 (6), 1106-17.

42. Remenyi, A.; Lins, K.; Nissen, L. J.; Reinbold, R.; Scholer, H. R.; Wilmanns, M., Crystal structure of a POU/HMG/DNA ternary complex suggests differential assembly of Oct4 and Sox2 on two enhancers. Genes Dev 2003, 17 (16), 2048-59.

43. Tapia, N.; MacCarthy, C.; Esch, D.; Gabriele Marthaler, A.; Tiemann, U.; Arauzo-Bravo, M. J.; Jauch, R.; Cojocaru, V.; Scholer, H. R., Dissecting the role of distinct OCT4-SOX2 heterodimer configurations in pluripotency. Sci Rep 2015, 5, 13533. 
44. Williams, D. C., Jr.; Cai, M.; Clore, G. M., Molecular basis for synergistic transcriptional activation by Oct1 and Sox2 revealed from the solution structure of the 42-kDa Oct1.Sox2.Hoxb1-DNA ternary transcription factor complex. J Biol Chem 2004, 279 (2), 1449-57.

45. Tantin, D., Oct transcription factors in development and stem cells: insights and mechanisms. Development 2013, 140 (14), 2857-66.

46. Tan, C.; Takada, S., Nucleosome allostery in pioneer transcription factor binding. Proc Natl Acad Sci U S A 2020, 117 (34), 20586-20596.

47. Huertas, J.; MacCarthy, C. M.; Scholer, H. R.; Cojocaru, V., Nucleosomal DNA Dynamics Mediate Oct4 Pioneer Factor Binding. Biophys J 2020, 118 (9), 2280-2296.

48. Tugarinov, V.; Hwang, P. M.; Ollerenshaw, J. E.; Kay, L. E., Cross-correlated relaxation enhanced $1 \mathrm{H}$ [bond]13C NMR spectroscopy of methyl groups in very high molecular weight proteins and protein complexes. J Am Chem Soc 2003, 125 (34), 10420-8.

49. Korzhnev, D. M.; Kloiber, K.; Kanelis, V.; Tugarinov, V.; Kay, L. E., Probing slow dynamics in high molecular weight proteins by methyl-TROSY NMR spectroscopy: application to a 723-residue enzyme. J Am Chem Soc 2004, 126 (12), 3964-73.

50. Lowary, P. T.; Widom, J., New DNA sequence rules for high affinity binding to histone octamer and sequence-directed nucleosome positioning. $J$ Mol Biol 1998, 276 (1), 19-42.

51. Yuan, H.; Corbi, N.; Basilico, C.; Dailey, L., Developmental-specific activity of the FGF-4 enhancer requires the synergistic action of Sox2 and Oct-3. Genes Dev 1995, 9 (21), 2635-45.

52. Li, G.; Levitus, M.; Bustamante, C.; Widom, J., Rapid spontaneous accessibility of nucleosomal DNA. Nat Struct Mol Biol 2005, 12 (1), 46-53.

53. Echigoya, K.; Koyama, M.; Negishi, L.; Takizawa, Y.; Mizukami, Y.; Shimabayashi, H.; Kuroda, A.; Kurumizaka, H., Nucleosome binding by the pioneer transcription factor OCT4. Sci Rep 2020, $10(1), 11832$.

54. Roberts, G. A.; Ozkan, B.; Gachulincova, I.; O'Dwyer, M. R.; Hall-Ponsele, E.; Saxena, M.; Robinson, P. J.; Soufi, A., Dissecting OCT4 defines the role of nucleosome binding in pluripotency. Nat Cell Biol 2021, 23 (8), 834-845.

55. Kassabov, S. R.; Bartholomew, B., Site-directed histone-DNA contact mapping for analysis of nucleosome dynamics. Methods Enzymol 2004, 375, 193-210.

56. Winger, J.; Nodelman, I. M.; Levendosky, R. F.; Bowman, G. D., A twist defect mechanism for ATP-dependent translocation of nucleosomal DNA. Elife 2018, 7.

57. Tugarinov, V.; Kay, L. E., An isotope labeling strategy for methyl TROSY spectroscopy. J Biomol NMR 2004, 28 (2), 165-72.

58. Sahu, S. C., Markley, J.L., Tonelli, M., Bahrami, A., Eghbalnia, H.R., Solution structure of the HMG box DNA-binding domain of human stem cell transcription factor Sox2. PDB, 2011.

59. Scaffidi, P.; Bianchi, M. E., Spatially precise DNA bending is an essential activity of the sox2 transcription factor. J Biol Chem 2001, 276 (50), 47296-302.

60. Xu, F.; Olson, W. K., DNA architecture, deformability, and nucleosome positioning. J Biomol Struct Dyn 2010, 27 (6), 725-39.

61. West, S. M.; Rohs, R.; Mann, R. S.; Honig, B., Electrostatic interactions between arginines and the minor groove in the nucleosome. J Biomol Struct Dyn 2010, 27 (6), 861-6.

62. Hall, M. A.; Shundrovsky, A.; Bai, L.; Fulbright, R. M.; Lis, J. T.; Wang, M. D., High-resolution dynamic mapping of histone-DNA interactions in a nucleosome. Nat Struct Mol Biol 2009, 16 (2), 1249 .

63. Ettig, R.; Kepper, N.; Stehr, R.; Wedemann, G.; Rippe, K., Dissecting DNA-histone interactions in the nucleosome by molecular dynamics simulations of DNA unwrapping. Biophys J 2011, 101 (8), 1999-2008.

64. Morrison, E. A.; Bowerman, S.; Sylvers, K. L.; Wereszczynski, J.; Musselman, C. A., The conformation of the histone $\mathrm{H} 3$ tail inhibits association of the BPTF PHD finger with the nucleosome. Elife 2018, 7.

65. Rohs, R.; West, S. M.; Sosinsky, A.; Liu, P.; Mann, R. S.; Honig, B., The role of DNA shape in protein-DNA recognition. Nature 2009, 461 (7268), 1248-53.

66. Haran, T. E.; Mohanty, U., The unique structure of A-tracts and intrinsic DNA bending. $Q$ Rev Biophys 2009, 42 (1), 41-81. 
67. Ozden, B.; Boopathi, R.; Barlas, A. B.; Lone, I. N.; Bednar, J.; Petosa, C.; Kale, S.; Hamiche, A.; Angelov, D.; Dimitrov, S.; Karaca, E., Differential Histone-DNA Interactions Dictate Nucleosome Recognition of the Pioneer Transcription Factor Sox. bioRxiv 2021, 2021.12.07.471700.

68. MacCarthy, C. M.; Huertas, J.; Ortmeier, C.; vom Bruch, H.; Reinke, D.; Sander, A.; Bergbrede, T.; Schöler, H. R.; Cojocaru, V., OCT4 interprets and enhances nucleosome flexibility. bioRxiv 2021, 2021.04.27.441583.

69. Li, S.; Zheng, E. B.; Zhao, L.; Liu, S., Nonreciprocal and Conditional Cooperativity Directs the Pioneer Activity of Pluripotency Transcription Factors. Cell Rep 2019, 28 (10), 2689-2703 e4.

70. Seiler, C. Y.; Park, J. G.; Sharma, A.; Hunter, P.; Surapaneni, P.; Sedillo, C.; Field, J.; Algar, R.; Price, A.; Steel, J.; Throop, A.; Fiacco, M.; LaBaer, J., DNASU plasmid and PSI:BiologyMaterials repositories: resources to accelerate biological research. Nucleic Acids Res 2014, 42 (Database issue), D1253-60.

71. Acton, T. B.; Gunsalus, K. C.; Xiao, R.; Ma, L. C.; Aramini, J.; Baran, M. C.; Chiang, Y. W.; Climent, T.; Cooper, B.; Denissova, N. G.; Douglas, S. M.; Everett, J. K.; Ho, C. K.; Macapagal, D.; Rajan, P. K.; Shastry, R.; Shih, L. Y.; Swapna, G. V.; Wilson, M.; Wu, M.; Gerstein, M.; Inouye, M.; Hunt, J. F.; Montelione, G. T., Robotic cloning and Protein Production Platform of the Northeast Structural Genomics Consortium. Methods Enzymol 2005, 394, 210-43.

72. Tugarinov, V.; Kanelis, V.; Kay, L. E., Isotope labeling strategies for the study of high-molecularweight proteins by solution NMR spectroscopy. Nat Protoc 2006, 1 (2), 749-54.

73. Luger, K.; Rechsteiner, T. J.; Richmond, T. J., Preparation of nucleosome core particle from recombinant histones. Methods Enzymol 1999, 304, 3-19.

74. Nodelman, I. M.; Patel, A.; Levendosky, R. F.; Bowman, G. D., Reconstitution and Purification of Nucleosomes with Recombinant Histones and Purified DNA. Curr Protoc Mol Biol 2020, 133 (1), e130. 75. Klinker, H.; Haas, C.; Harrer, N.; Becker, P. B.; Mueller-Planitz, F., Rapid purification of recombinant histones. PLoS One 2014, 9 (8), e104029.

76. Nodelman, I. M.; Bleichert, F.; Patel, A.; Ren, R.; Horvath, K. C.; Berger, J. M.; Bowman, G. D., Interdomain Communication of the Chd1 Chromatin Remodeler across the DNA Gyres of the Nucleosome. Mol Cell 2017, 65 (3), 447-459 e6.

77. Hixson, S. H.; Hixson, S. S., P-Azidophenacyl bromide, a versatile photolabile bifunctional reagent. Reaction with glyceraldehyde-3-phosphate dehydrogenase. Biochemistry 1975, 14 (19), 4251-4.

78. Delaglio, F.; Grzesiek, S.; Vuister, G. W.; Zhu, G.; Pfeifer, J.; Bax, A., NMRPipe: a multidimensional spectral processing system based on UNIX pipes. J Biomol NMR 1995, 6 (3), 27793.

79. Sun, S.; Gill, M.; Li, Y.; Huang, M.; Byrd, R. A., Efficient and generalized processing of multidimensional NUS NMR data: the NESTA algorithm and comparison of regularization terms. $J$ Biomol NMR 2015, 62 (1), 105-117.

80. Goddard, T. D.; Kneller, D. G. SPARKY 3, University of California, San Francisco. 